\title{
A Study on Surface Modification of Al7075-T6 Alloy against Fretting Fatigue Phenomenon
}

\author{
E. Mohseni, E. Zalnezhad, Ahmed A. D. Sarhan, and A. R. Bushroa \\ Department of Mechanical Engineering, Faculty of Engineering, University of Malaya, 50603 Kuala Lumpur, Malaysia \\ Correspondence should be addressed to E. Zalnezhad; erfan@um.edu.my
}

Received 1 December 2013; Revised 25 March 2014; Accepted 16 April 2014; Published 22 June 2014

Academic Editor: Shuichi Miyazaki

Copyright ( 2014 E. Mohseni et al. This is an open access article distributed under the Creative Commons Attribution License, which permits unrestricted use, distribution, and reproduction in any medium, provided the original work is properly cited.

\begin{abstract}
Aircraft engines, fuselage, automobile parts, and energy saving strategies in general have promoted the interest and research in the field of lightweight materials, typically on alloys based on aluminum. Aluminum alloy itself does not have suitable wear resistance; therefore, it is necessary to enhance surface properties for practical applications, particularly when aluminum is in contact with other parts. Fretting fatigue phenomenon occurs when two surfaces are in contact with each other and one or both parts are subjected to cyclic load. Fretting drastically decreases the fatigue life of materials. Therefore, investigating the fretting fatigue life of materials is an important subject. Applying surface modification methods is anticipated to be a supreme solution to gradually decreasing fretting damage. In this paper, the authors would like to review methods employed so far to diminish the effect of fretting on the fatigue life of Al7075-T6 alloy. The methods include deep rolling, shot peening, laser shock peening, and thin film hard coatings. The surface coatings techniques are comprising physical vapor deposition (PVD), hard anodizing, ion-beam-enhanced deposition (IBED), and nitriding.
\end{abstract}

\section{Introduction}

Fretting fatigue phenomenon occurs when two surfaces in contact simultaneously encounter sliding movements and fluctuating loads. Fretting fatigue also occurs when an oscillatory movement with low amplitude between two surfaces is remaining for a large number of cycles [1]. This event can result in two different types of damage: fretting fatigue and fretting wear [2-4]. Bearings, bolted, steel cables, riveted connections and shafts, and steam or gas turbines are common examples of engineering applications facing high fretting fatigue damage risk [5-8]. In contrast to normal fatigue conditions, fretting fatigue may significantly reduce the endurance limit of components. Fretting fatigue may occur in bending, torsion, and even tension forms [9]. Figure 1(a) illustrates the fretting corrosion at an axle-cylinder contact. Figure 1(b) shows fretting wear on the cap screw threads. The fretting fatigue in bolted flanges is presented in Figure 2 $[10,11]$. Fretting fatigue is triggered by cracks formed in either surface. It is more serious than fretting wear and fretting corrosion because it can lead to severe component failure.
The fretting fatigue mechanism is schematically arranged and illustrated in Figure 3. Two fretting pads are pushed opposite to the specimen by a load called contact force, $P$. The component then encounters a cyclic load, Q. Elastic elongation takes place in the sample along the contact zone that causes the fretting fatigue in component. The material's resistivity against fretting fatigue is influenced by contact configuration, slipping amplitude, or surface conditions like lubrication, hardness, friction coefficient, and roughness [12].

Generally, three basic means of choosing preventative measures are introduced.

(1) Change in design: design optimization involves change in contacting materials and component geometry, and it is a basic method of suppressing fretting [13].

(2) Use of lubricants: using a suitable lubricant (e.g., solid, liquid, or grease) is another possible way of providing practical reduction in fretting damage [14]. 


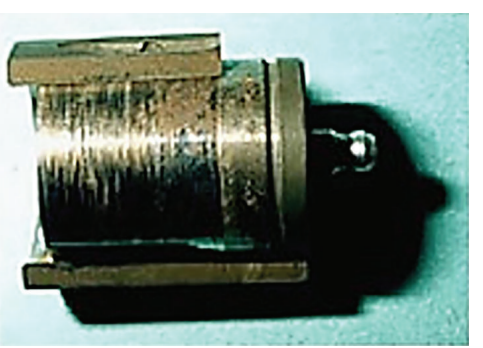

(a)

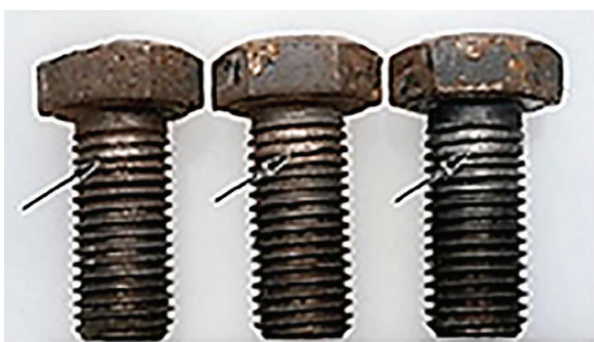

(b)

FIGURE 1: (a) Fretting corrosion at an axle-cylinder contact and (b) fretting wear on the threads of the caps crews [11].
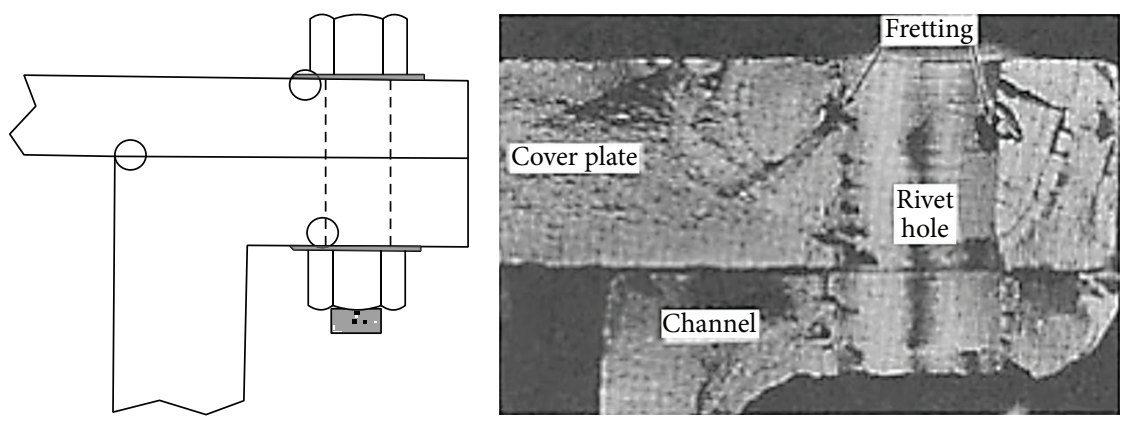

FIGURE 2: Fretting fatigue in bolted flanges [11].

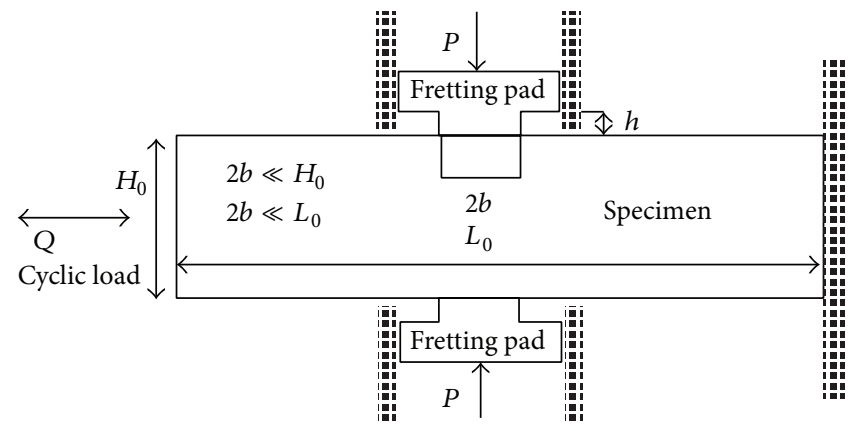

FIGURE 3: The schematic view of a fretting fatigue arrangement [11]

(3) Application of surface engineering: the introduction of surface treatments is likely an ideal solution to diminish fretting damage [15-18].

As mentioned earlier, the fretting fatigue behavior of materials can be significantly enhanced by different surface treatment techniques [19-23] including induction hardening, nitriding, case hardening, shot peening, roll peening, and laser shock peening $[24,25]$. The reduction coefficient of fretting fatigue life for the number of engineering alloys is given in Table 1 [26]. The material's durability to fretting fatigue is significantly increased by enhanced surface conditions such as roughness, hardness, and lowered friction coefficient, something achievable by surface treatment techniques like surface-coatings, deep rolling, and shot peening that may postpone crack initiation.
Improving the mechanical properties of surface by leaving the treated region in compressive residual stress states has the major benefit [27-32].

Automobile parts, fuselage, aircraft engines, and energy saving strategies generally promote the research interest in the area of lightweight materials by mainly aluminum alloys. The pure aluminum is not suggested to be used as structural parts since it does not result in satisfactory mechanical strength. Hence, in practical applications, it is essential to improve the surface properties, especially prior to aluminum coming in contact with other parts $[33,34]$.

Aerospace structural fastened joints utilize Al 7075-T6 and fretting fatigue damage can result in catastrophic failures under fluctuating loading $[35,36]$. Aluminum alloy $7075-$ T6 has high ratio of strength to weight and low specific weight besides high thermal and electrical conductivity. The formation of thin hard coatings on material surfaces is one 
TABLE 1: The reduction coefficient of fretting fatigue life for some engineering alloys [26].

\begin{tabular}{|c|c|c|c|c|c|c|c|}
\hline $\begin{array}{l}\text { Fatigue } \\
\text { specimen }\end{array}$ & Contact pad & $\begin{array}{c}\text { Contact } \\
\text { pressure }(\mathrm{MPa}) \\
\end{array}$ & $\begin{array}{c}\text { Fatigue mean } \\
\text { stress }(\mathrm{MPa})\end{array}$ & $\begin{array}{l}\text { Fatigue strength } \\
\text { unfretted }(\mathrm{MPa})\end{array}$ & $\begin{array}{l}\text { Fatigue strength } \\
\text { fretted }(\mathrm{MPa})\end{array}$ & $\begin{array}{c}\text { Strength } \\
\text { reduction factor }\end{array}$ & $\begin{array}{l}\text { Relative slip } \\
\text { range }(\mu \mathrm{m})\end{array}$ \\
\hline \multicolumn{8}{|c|}{ Steels } \\
\hline 3.5 NiCrMoV & 1CrMo & 30 & 0 & \pm 300 & \pm 140 & 2.1 & 15 \\
\hline 3.5 NiCrMoV & 1CrMo & 30 & 300 & \pm 215 & \pm 60 & 3.6 & 6.2 \\
\hline 3.5 NiCrMoV & 1CrMo & 300 & 0 & \pm 300 & \pm 130 & 2.3 & 12 \\
\hline 3.5 NiCrMoV & 1CrMo & 300 & 300 & \pm 215 & \pm 60 & 3.6 & 4 \\
\hline 3.5 NiCrMoV & $2014 \mathrm{~A}$ & 30 & 0 & \pm 300 & \pm 140 & 2.1 & 1.5 \\
\hline 3.5 NiCrMoV & $2014 \mathrm{~A}$ & 30 & 300 & \pm 215 & \pm 75 & 2.9 & 6.8 \\
\hline $18 \mathrm{M} 114 \mathrm{Cr}$ & 3.5 NiCrMoV & 20.7 & 0 & \pm 250 & \pm 100 & 2.5 & 10 \\
\hline $18 \mathrm{M} 114 \mathrm{Cr}$ & 3.5NiCrMoV & 20.7 & 300 & \pm 125 & \pm 50 & 2.5 & 4.5 \\
\hline $18 \mathrm{M} 114 \mathrm{Cr}$ & 3.5NiCrMoV & 20.7 & 0 & \pm 250 & \pm 165 & 1.5 & 17.4 \\
\hline $18 \mathrm{M} 114 \mathrm{Cr}$ & 3.5 NiCIMoV & 20.7 & 300 & \pm 185 & \pm 70 & 2.6 & 6.7 \\
\hline \multicolumn{8}{|c|}{ Aluminum } \\
\hline $2014 \mathrm{~A} \mathrm{Al}$ & 3.5 NiCrMoV & 30.8 & 75 & \pm 140 & \pm 15 & 9.3 & 2 \\
\hline $2014 \mathrm{~A} \mathrm{Al}$ & 3.5 NiCrMoV & 30.8 & 125 & \pm 135 & \pm 12.5 & 10.8 & 1.5 \\
\hline $2014 \mathrm{~A} \mathrm{Al}$ & 3.5 NiCrMoV & 30.8 & 125 & \pm 135 & \pm 50 & 2.7 & 9.6 \\
\hline \multicolumn{8}{|l|}{ Peened } \\
\hline \multicolumn{8}{|c|}{ Aluminum } \\
\hline $2014 \mathrm{~A}$ & BS S98 & 103.5 & 0 & \pm 148 & \pm 72 & 2.05 & 2 \\
\hline $2014 \mathrm{~A}$ & BS S98 & 103.5 & 0 & \pm 148 & \pm 47 & 3.14 & 4.2 \\
\hline $2014 \mathrm{~A}$ & BS S98 & 103.5 & 0 & \pm 148 & \pm 36 & 4.11 & 8.35 \\
\hline $2014 \mathrm{~A}$ & BS S98 & 103.5 & 0 & \pm 148 & \pm 36 & 4.11 & 17.4 \\
\hline \multicolumn{8}{|c|}{ Titanium } \\
\hline Ti6Al4V & Ti6Al4V & 20 & 61.25 & \pm 260 & \pm 125 & 2.1 & 30 \\
\hline
\end{tabular}

of the best ways to enhance the material wear resistance. Hard coatings also appear to be encouraging by means of the feasibility of approaching high strength, hardness, and concurrently high protective and decorative surface properties [37].

This study focuses on the variety of surface treatments available to mitigate the fretting fatigue of aluminum 7075T6. Deep rolling, shot peening, TiN coating, CrN coating, and nitriding surface treatments are discussed.

\section{Surface Treatment Using Mechanical Techniques}

2.1. Deep Rolling. Deep rolling (DR) includes a ball or roller type tool to induce surface-compressive residual stress. Such stress enhances the fatigue resistance of engineering components and materials. A deep rolling fixture is illustrated in Figure 4. This technique is distinct from roller burnishing whose main purpose is to achieve an exceptionally wellpolished surface. The ball or roller produces a longitudinal groove as it comes in contact with the component's surface. A plastic region along with an elastic zone couples with this groove. Upon separation from the roller, a large, compressive residual stress is produced on the surface as a result of recovering the elastic zone. Surface rolling residual stresses are generally consequent to the interface between the plastic and elastic regions that result from the pressure between the roller and the contact surface. Specific parameters can considerably affect the process of deep rolling followed by near-surface residual stress; force of rolling is recognized to be the main one. Very low level of rolling forces has no serious effect on the behavior of fatigue, but considerably high force may make it even worse, for example, by initiation of microcracks. As such, it appears that only optimized rolling forces are able to promote fatigue strength [38].

The aero and automobile industries (in particular crankshafts) commonly utilize the DR technique to develop fatigue resistance. Compared with other methods, DR has two distinct advantages: (i) lower surface roughness and (ii) greater compressive residual stress depth.

2.2. Shot Peening. Shot peening (SP), for decades, was known as a surface treatment with questionable benefits about cyclic loading [39]. The inconsistent results were partially due to ignorance with respect to the shot peening process and partly result from a lack of proper background that would allow the characterization of the role that surface modifications produced by shot peening play in fatigue damage. Nowadays, the control parameters of shot peening performance, such as intensity, media, and coverage, are well understood, and new designation of controlled shot peening (CSP) has emerged. The CSP or SP is a cold work process accomplished 


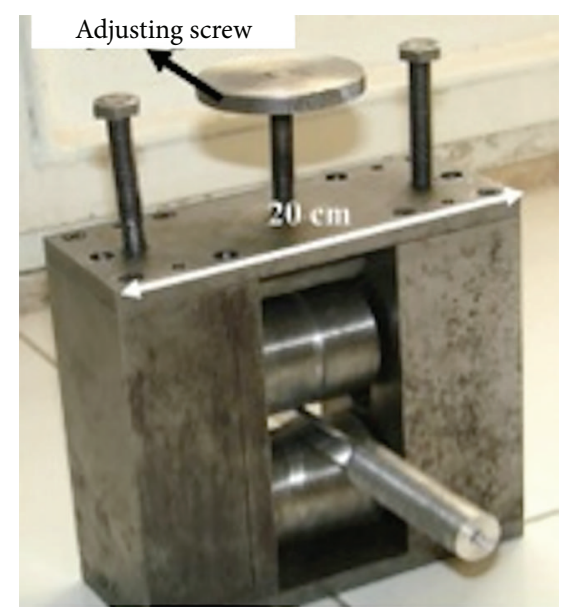

FIGURE 4: The fixture used for DR the specimens [38].
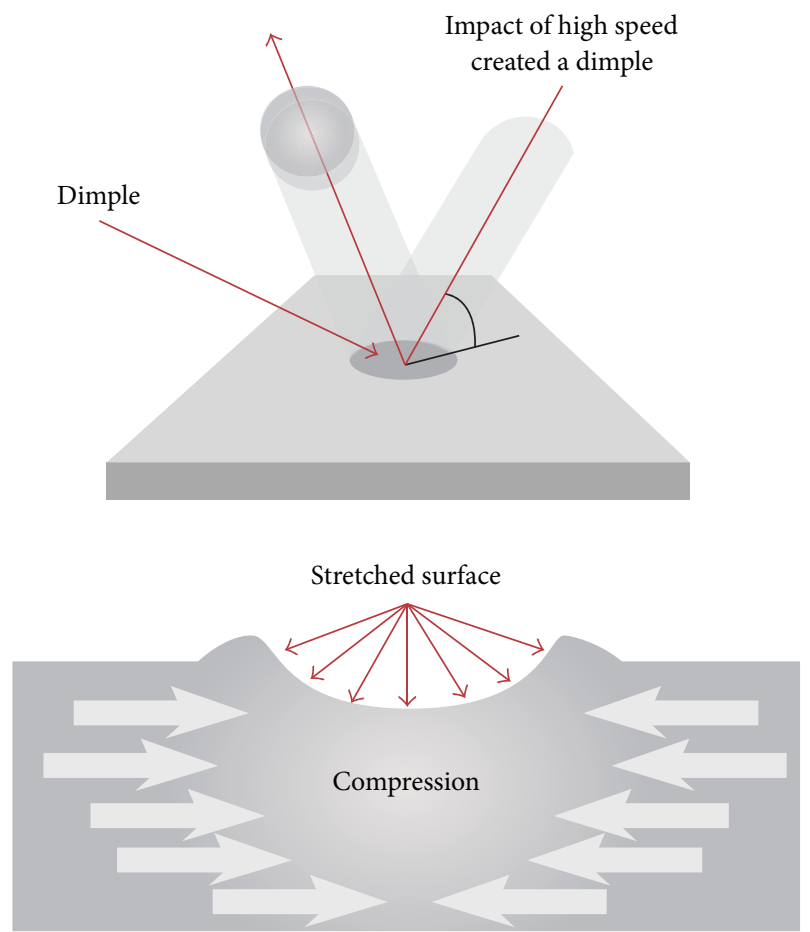

FIGURE 5: Schematic of shot peening bombardment on a surface with small high quality spherical media [5].

by bombarding the workpiece surface with small-diameter ferrous and nonferrous spherical shots. A schematic of the shot peening process to induce compressive residual stress is shown in Figure 5.

SP is widely applicable for enhancing the industrial component's fatigue behavior, particularly in the car industry [40-43]. SP even acts as a forming process in the production of large, thin aero industrial components including wide panels. SP is known to harden a material's surface and consequently increase its strength. The surface modifications yielded by SP are (a) surface roughening; (b) an increased, near-surface, dislocation density (strain hardening); and (c)

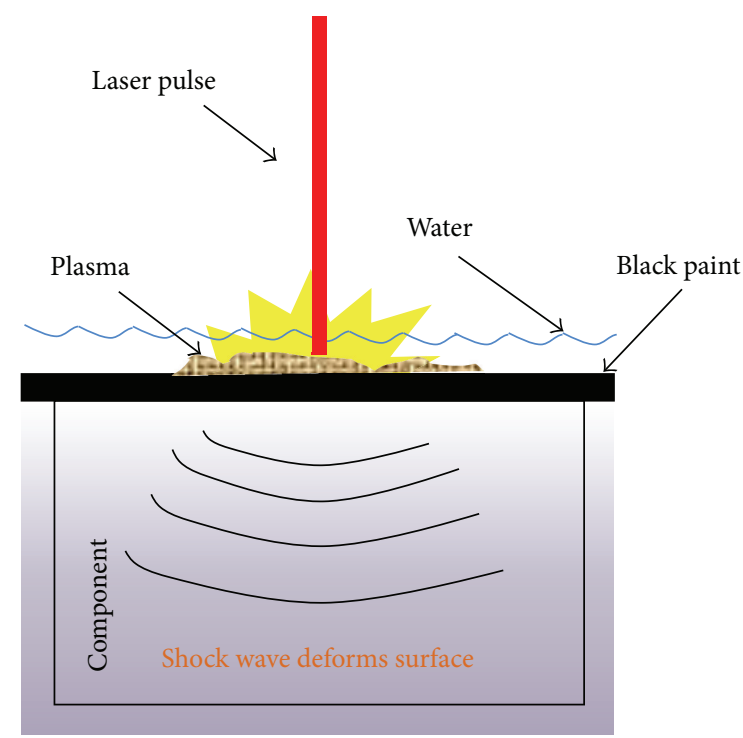

FIGURE 6: Schematic of the laser peening process.

the development of a characteristic residual stress profile [4446].

2.3. Laser Shock Peening. Laser shock peening (LSP) is a promising surface treatment technique which has demonstrated effectiveness in enhancing the fatigue properties of a number of metals and alloys. The process was originally developed at the Battelle Columbus Laboratory in the 1970s [47-51]. The LSP procedure is illustrated schematically in Figure 6. Since then, considerable attention has been directed to potential LSP applications in the aerospace and automotive industries. The beneficial effects of LSP on the static, cyclic, fretting fatigue and stress corrosion performance of aeronautical and automotive aluminum alloys, steels, and nickelbased alloys have been confirmed [52-59]. LSP has also been successfully engaged in upgrading the resistance of aircraft gas turbine engine blades to foreign object damage. Since laser beams can be easily directed to fatigue-critical areas, LSP technology is expected to be widely applicable to improving the fatigue properties of metals and alloys, particularly those that respond positively to shot peening.

\section{Mechanical Techniques for Improving the Fretting Fatigue Life of Al 7075-T6}

3.1. Deep Rolling. Majzoobi et al. [38] looked into how deep rolling (DR) affects the fretting fatigue life of Al 7075-T6. In order to assess the effectiveness, they compared shot peening (SP) with deep rolling (DR) on the fretting fatigue behavior of Al 7075-T6. In their study, the following experiments were examined: (i) fretting fatigue tests on roll-peened specimens with high force of rolling, (ii) fretting fatigue tests on intact specimens, (iii) fretting fatigue tests on shot-peened specimens, (iv) normal fatigue tests on virgin specimens, and (v) fretting fatigue tests on roll-peened specimens with low force of rolling. 


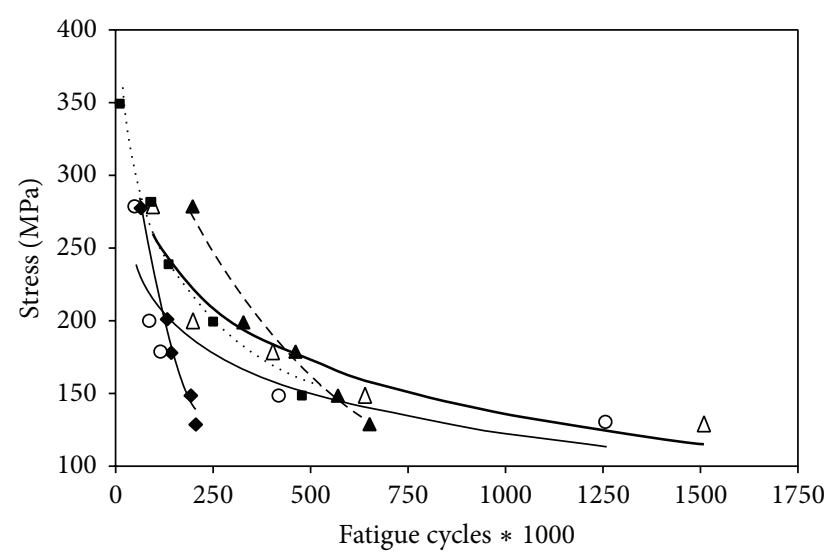

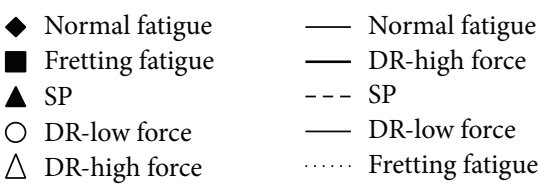

FIGURE 7: S-N curves for various fatigue testing conditions [38].

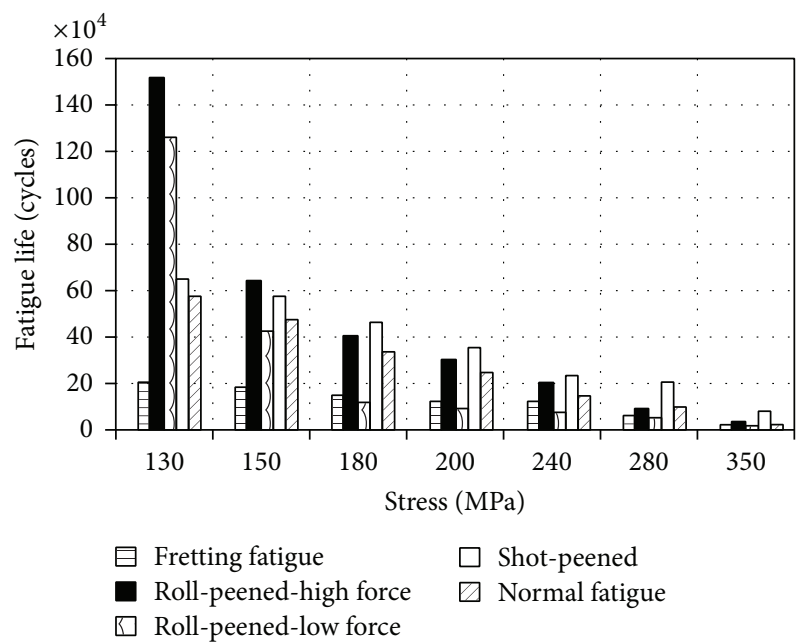

FIGURE 8: Bar chart for various fatigues testing conditions [38].

The experimental results are graphically illustrated in Figure 7, where it is evident that the fretting fatigue tests on intact samples (with no surface treatment) produced the lowest fatigue life. However, the situation differed in the case of the surface-treated samples. The bar chart in Figure 8 depicts the influence of different surface treatment techniques on the fretting fatigue behavior of the material. Also, apparently, the results (Figure 7) indicate that fretting fatigue decreases normal fatigue life at a stress of $130 \mathrm{MPa}$ by roughly $67 \%$. The fatigue life reduction rate, though, diminishes with rising stress [38].

The profiles of residual stress formed by DR in the $x$, $y$, and $z$ directions are shown in Figure 9 for the roller's linear motion $x x$, the roller's transverse displacement $y y$, and load $z z$ (Figure 10). Obviously, the stress in the $y$ direction is more significant than the other two components,

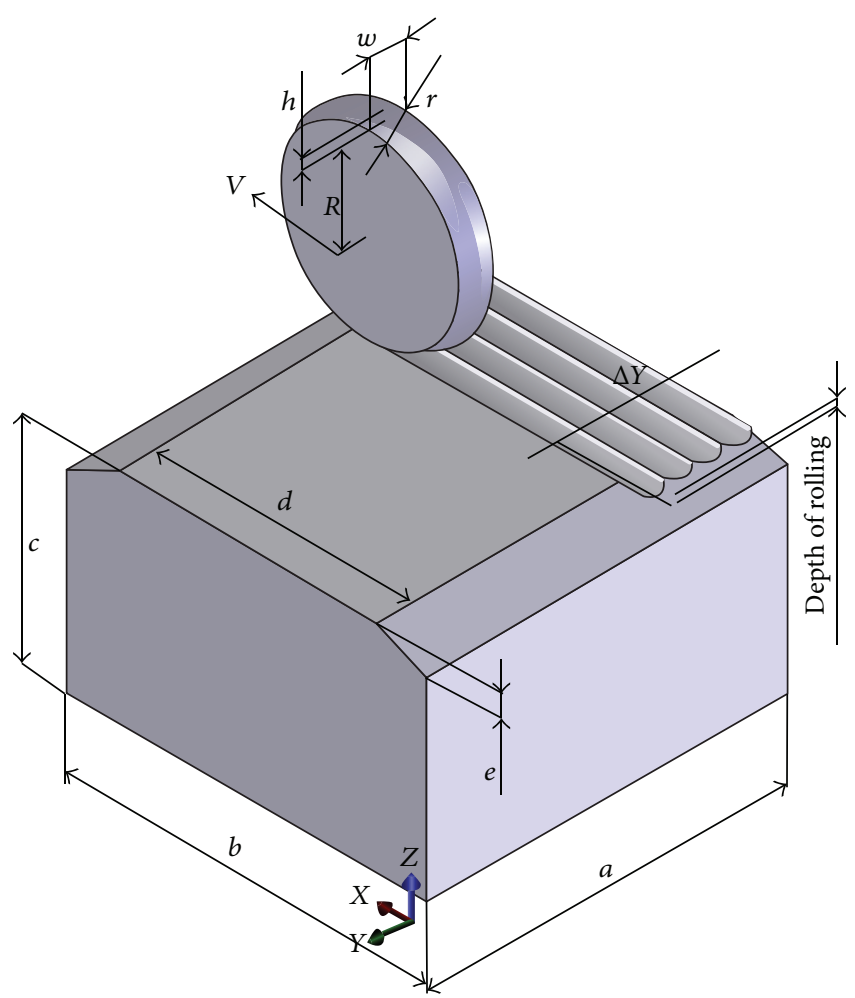

FIGURE 9: Residual stress profiles induced by DR in three directions [38].

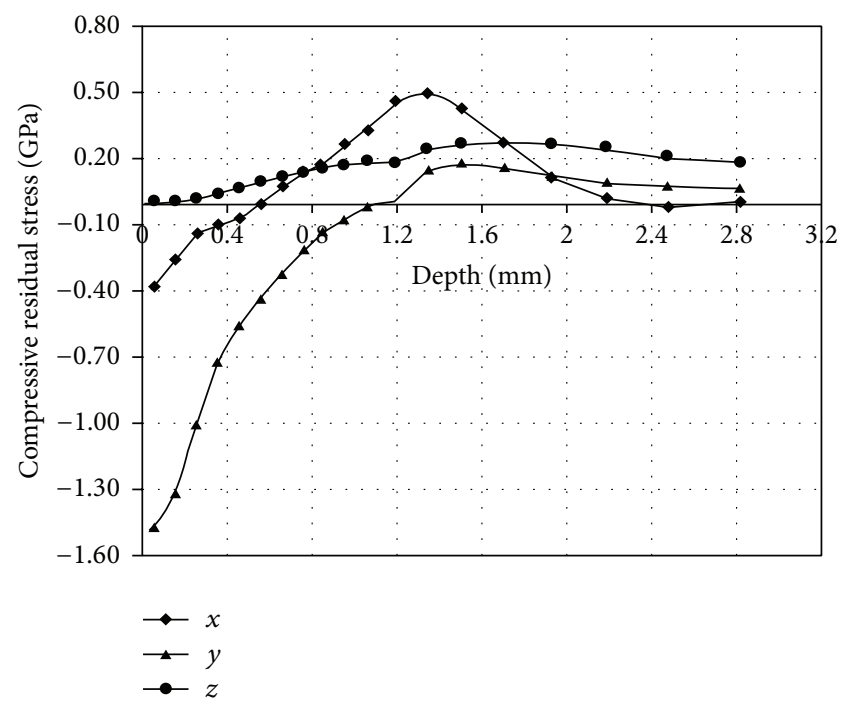

FIgURE 10: The model of deep rolling (not scaled) used in the simulations [38].

and it runs perpendicularly to the rolling direction. It should be mentioned that the oscillatory motion of contacting surfaces in the fretting fatigue tests, for example, between the specimen and pad, is in the $x$-direction [38].

Results provide evidence that for low cycle fatigue (LCF) SP remains exceptionally high, up to approximately 300,000 cycles. For more than 300,000 cycles, the influence of DR on resistance to fretting fatigue is superior to SP where fatigue 


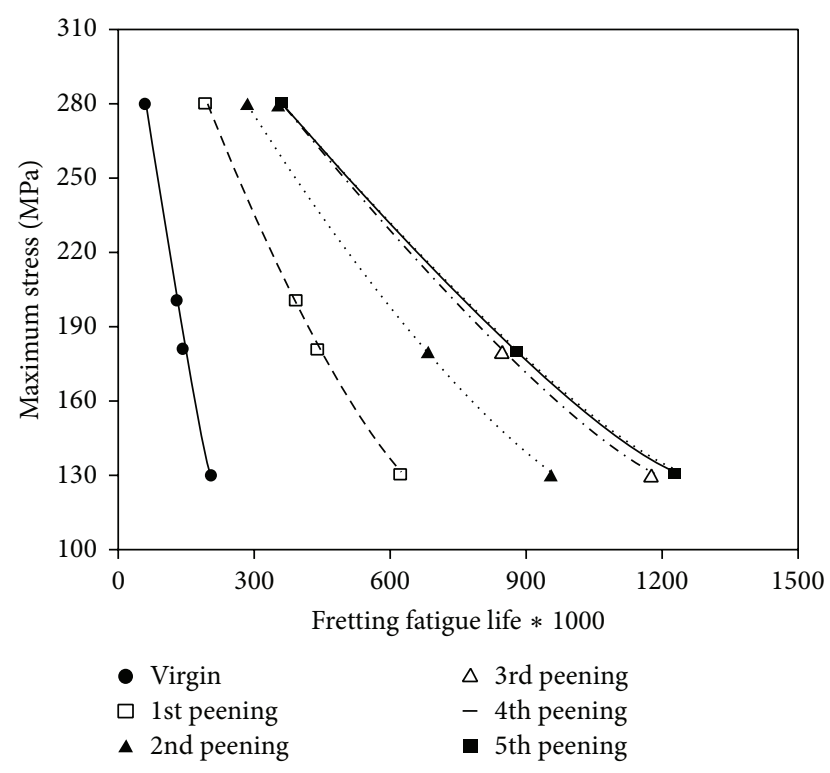

FIGURE 11: Variation of fatigue life versus maximum stress for multiple reshot peening [60].

cycles increase by $700 \%$ (at $130 \mathrm{MPa}$ stress) at high rolling force deep rolling. The rate of increase in fatigue life slows down as the applied stress diminishes so that for the stress of $150 \mathrm{MPa}$ the fretting fatigue life increases about $400 \%$, while for the stress of $280 \mathrm{MPa}$ the fatigue life increase is only about $50 \%[38]$.

3.2. Shot Peening. Much like DR, SP produces a layer of compressive residual stress near the workpiece surface. The distribution and depth of residual stress are potentially affected by a variety of parameters such as material, shot diameter, target material, duration, intensity of exposure, and shot velocity. SP is widely utilized for enhancing the fatigue life of industrial components, more so in the car industry [40-43].

Majzoobi et al. [38] studied the influence of shot peening and deep rolling on the fretting fatigue life of Al 7075-T6. Based on their results, which are illustrated in Figures 7 and 8, the SP technique maintains a superior performance position to DR at low cyclic fatigue (LCF). The shot peening technique improves fretting fatigue life by a significant $300 \%$. Majzoobi and Ahmadkhani in a similar endeavor investigated the influence of regular reshot peening on the resistance of Al7075-T6 against fretting fatigue [60]. They found that it is possible to considerably enhance the material's behavior against fretting fatigue with reshot peening. After 5 reshot peening processes, the fretting fatigue life of Al7075-T6 improved by $600 \%$. Figure 11 presents the variation of fretting fatigue life versus maximum stress for each stage of reshot peening. It is clear that the gap between the curves becomes wider at less stress, which is supported by the bar chart in Figure 12 where fretting fatigue life improvement at lower stresses is more considerable than at higher stresses [60].

Reshot peening is more efficient during initial processes. For example, an almost $100 \%$ increase in fatigue life was

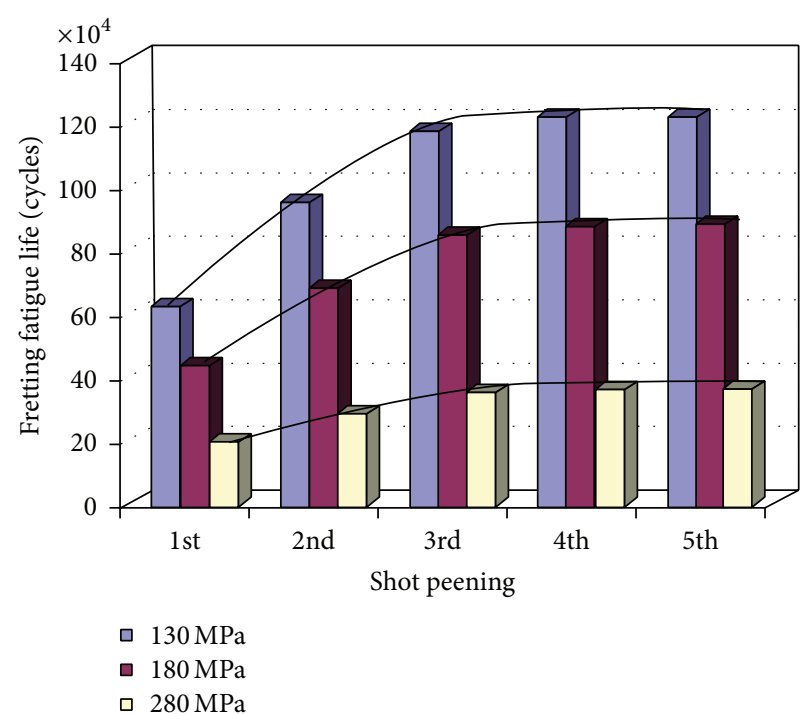

Figure 12: Variation of fatigue life versus the number of reshot peenings for different maximum stresses [60].

observed for a first round of reshot peening. This increase is logarithmically decreased for subsequent reshot peenings. It is reported that the 5 th reshot peening produced a negligible improvement of less than $2 \%$.

The improvement in fatigue life as a result of reshot peening can be credited to (i) the closing of small cracks that had already initiated and grown on the component's contacting surface, (ii) removal of debris created by wear and the fretting phenomenon from the shot peening process, (iii) the recreation of a layer of compressive residual stress through the reshot peeing process, and (iv) a combination of reasons (i) to (iii) [60].

From a comparative study between DR and SP, it is concluded that (i) at low cyclic fatigue the SP technique improves the material's fretting fatigue behavior more efficiently than DR; (ii) a 300\% improvement has been attained for the SPtested specimen; however, (iii) the influence of DR on fretting fatigue resistance proved more effective for high cycle fatigue; for example, there was an increase of up to $700 \%$ for DR at higher forces of rolling; (iv) with decreasing the force of rolling, the trend of increase in fatigue life slowed down; (v) the surface modification technique has direct impact on the friction coefficient such that the highest and lowest friction coefficients, 0.70 and 0.45 , were achieved for the low force deep-rolled and intact sample, respectively.

3.3. Laser Shock Peening. The resistance of alloys and metals to fretting fatigue and fatigue is normally increased by laser shock peening (LSP) and laser peening [61]. The boost in resistance is accomplished by a high energy pulsed laser that creates residual compressive stresses and strain hardening into the surface of the part being laser peened. Compared with shot peening, the compressive residual stresses produced by laser shock peening penetrate deeper into the surface than those obtained by shot peening. Thus, significantly 

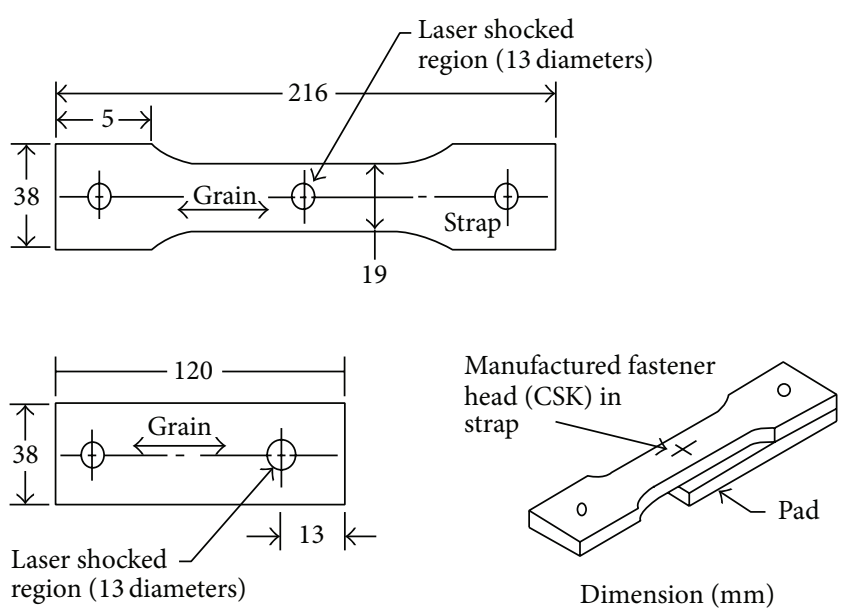

FIGURE 13: Ferreting fatigue specimen configuration [62].

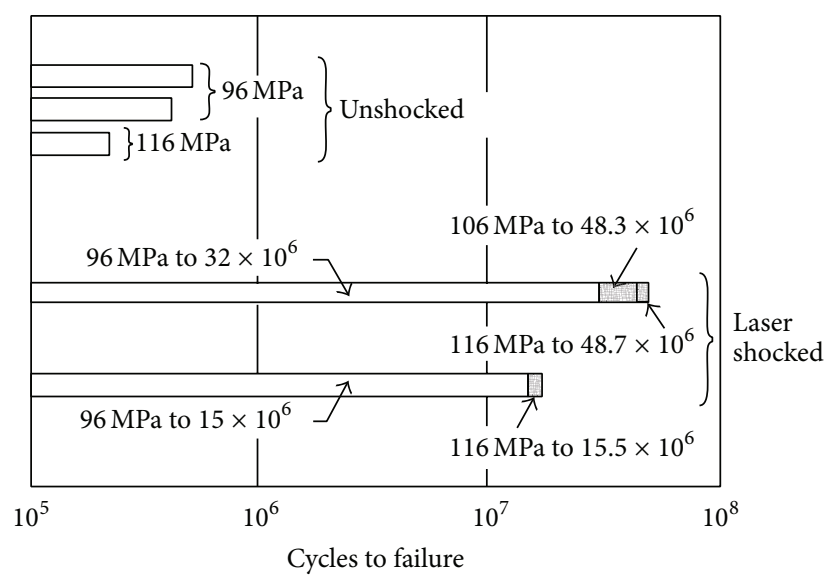

FIGURE 14: Increased resistance to ferreting fatigue around fastener holes after laser shock peening aluminum 7075-T6 [62].

greater fatigue resistance promotion is noted after laser shock peening.

Laser shock peening is the most effective against fretting fatigue [62]. Dog-bone specimens and pads of aluminum 7075-T6 alloy were laser treated around a simulated fastener hole located in each piece (Figure 13); the pieces were then fixed firmly together through the holes with a manufactured fastener. The fatigue test at $R=0.1$ was carried out on this combination. The stress differential between the smaller cross-section of the dog-bone and the larger cross-section of the pad created an elongation differential between each piece during a cycle, leading to fretting around the fastener hole. The results are provided in Figure 14. The tests were initially conducted at $96 \mathrm{MPa}$. Upon achieving a lengthy life, the stress was increased by $10 \%$ until failure occurred after a few hundred thousand cycles. LSP expanded fretting fatigue life even at $113 \mathrm{MPa}$.

Earlier, it has been discussed that SP is a successful technique, whereby the component surface is deformed plastically using multiple overlapping impacts of ceramic or metal shot $[63,64]$. However, the depth of the compressive residual stress is practically only about $250 \mu \mathrm{m}$, maintaining low fretting fatigue resistance. Accordingly, King et al. [52] demonstrated a comparison between SP and LSP. Compared to SP, LSP is able to produce compressive stresses to greater depths, $\sim 1.5 \mathrm{~mm}$, while at the same time keeping lower work hardening levels [65-67].

King et al. [52] claimed that the fretting fatigue loading of dovetail biaxial rig samples with contact surfaces treated with combined SP and LSP results in considerable stress relaxation that penetrates $0.5 \mathrm{~mm}$ deep. The penetration of compressive residual elastic strain $(\sim 1.5 \mathrm{~mm})$ is unaffected. Their study reports that fretting results in plastic relaxation of the misfit parallel to the fretting direction which extends roughly $0.4 \mathrm{~mm}$ below the fretted and laser peened surface, despite the less significant misfit relaxation that is usual to the fretting direction. Basically, the extended depth of compressive residual stress produced by laser shock peening as opposed to shot peening $(1.5 \mathrm{~mm}$ instead of $0.3 \mathrm{~mm})$ is a significant consideration in enhancing the tolerance of components to fretting damage.

\section{Coating Surface Treatments}

4.1. Physical Vapor Deposition (PVD). PVD coatings are popular in many cutting applications mostly due to their high hardness $[68,69]$. Other applications are known to take advantage of these coatings for upgrading the fretting fatigue and wear resistance of contacting components [7072]. With the advent of modern technologies like vacuum processing, high power laser, and progress in materials such as composites and ceramics, surface modification methods based on current technologies have found additional demand with respect to traditional surface modifications ranging from painting and glazing to electroplating and gas carburizing over the past decade [22]. Vacuum coating procedures carry the potential to apply higher-hardness coatings than any metal. PVD is one of the vacuum coating techniques known to condensate from vapor phase to solid phase, having the film material deposited atom by atom on the substrate. PVD metal coatings like silver and gold were conventional means of avoiding fretting failure [73]. Studies have reported that under fretting amplitudes of about $50 \pm 100 \mathrm{~mm}$ metal coatings like zirconium and chromium make durable films [74]. This technology permits coating deposition at temperatures as low as $200^{\circ} \mathrm{C}\left(390^{\circ} \mathrm{F}\right)$. Maintaining a low temperature facilitates the coating of materials with neither loss of hardness, distortion nor reduction in corrosion resistance, while PVD coatings experience no performance deterioration in comparison with materials deposited at higher temperatures. Improved surface hardness and higher service temperatures are obtainable with PVD [75-77]. Thermal evaporation, ion plating, and sputtering are the three main techniques of applying PVD coatings [78]. More recently, PVD coating has become probably one of the most widely used and successful sorts of coating meant to improve fretting fatigue life [79].

4.2. Hard Anodizing. Hard anodize coating is a very effective surface treatment employed with the aim of reducing 
TABLE 2: The list of the aluminum alloys which should be avoided to hard anodizing [83].

\begin{tabular}{l}
\hline Difficult Al alloys for hard anodizing \\
\hline 2011 \\
2017 \\
2024 \\
7075 \\
\hline
\end{tabular}

Cast and wrought alloys with

$\mathrm{Cu}>4 \%$ or $\mathrm{Si}>7 \%$

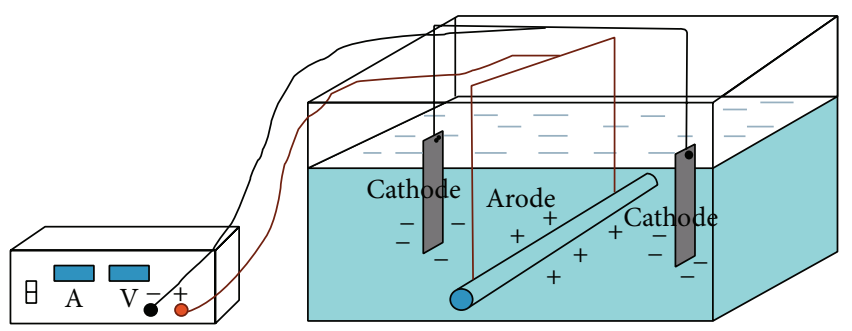

FIGURE 15: The schematic of hard anodizing process [83].

the destructive influence of fretting fatigue. Hard anodizing is encouraging to obtain high strength and hardness, while simultaneously presenting fine surface decorative and protective properties. This coating resulting by an electrochemical process performs stable oxide layers on the surface of the metal. Anodic coating can be deposited to surfaces of aluminum through different electrolytes with AC, DC, or a combination of both, to enhance the metal hardness. Hard-anodized coating is not accepted by all types of aluminum alloys and thus is not applicable in such cases. Aluminum alloys with high silicon or copper content are prone to not being very hard and porous. Table 2 lists some of the alloys that are difficult to be coated and should be practically avoided [80-83]. Pure aluminum coating via magnetron sputtered Al7075-T6 alloy may facilitate substrate hard anodizing.

Optimizing the effect of each parameter during the hard anodizing process is a critical requirement to improve surface hardness [84, 85]. Anodizing equipment (Figure 15) comprises electrolytic solution, a power supply, cathode (stainless steel), and anode (substrate material). A thin oxide layer is formed on account of the reaction between the oxygen and the substrate; the layer is abrasion-resistant and durable, while hydrogen is produced at the cathode. The anodizing generates uniform oxidation layer (coating) that is much denser and harder than natural oxidation. Moreover, thanks to the hard anodizing coating, the substrate melting point is augmented from about $650^{\circ} \mathrm{C}$ to approximately $2000^{\circ} \mathrm{C}$, which is enough to sustain the mechanical properties at elevated temperatures.

4.3. Ion Beam Enhanced Deposition (IBED). Ion beam enhanced deposition (IBED) is a process in which PVD coated films are bombarded by an independently produced flux of ions at the same time $[86,87]$. Atomic displacements at the bulk and the surface and the amplified migration of atoms within the surface are two results of the massive energy applied to the deposited atoms [88]. The ensuing atomic motions are responsible for improving the film properties as opposed to similar films generated by PVD in the absence of ion bombardment. The advantages of ion-beam-assisted deposition are low deposition temperature, control of stress level, high density, control of microstructure (nanocrystaline, metastable crystalline, or amorphous), precise modulation of composition with depth and high versatility for metals, ceramics, semiconductors, and dielectrics. The limitations of ion-beam-assisted deposition are relatively high cost and line-of-sight [89]. When ions are reactive, compounds such as TiN, Si3N4, and $\mathrm{BN}$ can be synthesized at fairly low temperatures [90-92]. Thin films of varying stoichiometry or functionally graded thin films can also be produced by adjusting the ratio of reactive ions to atoms reaching the substrate surface [93].

4.4. Nitriding. Nitriding is a heat-treating process that diffuses nitrogen into a metal surface to create a casehardened surface. It is commonly used on steel, aluminum, titanium, and molybdenum. The major types comprise ion, plasma, laser, and gas nitriding.

Plasma nitriding is a thermochemical treatment method with several advantages such as control of nitrided layer depth and phase formation $[94,95]$. This kind of treatment requires special equipment and high ionizing energy. The two major plasma processes developed for titanium nitride synthesis are ion nitriding and PVD [96]. One disadvantage of plasma nitriding is that it reduces the fretting fatigue strength of aluminum alloys, a problem that can nevertheless be overcome by lowering the processing temperature [97]. Ion-beam nitriding, which includes the high-energy end spectrum, is an alternative method of hardening aluminum and titanium alloy surfaces. The treated surface is encountered to the ion beam using $\mathrm{N}_{2}$ and $\operatorname{Ar}[98,99]$.

Laser nitriding melts the surface, up to 1.5 am deep, using a focused laser beam in a nitrogen gas environment to produce a hard layer of titanium nitride. Surface cracking is the main drawback with laser nitriding of titanium alloys [100]. The main disadvantages are special equipment requirement and dependency on the material's geometry.

Gas nitriding is deemed a promising method for engineering applications, as it forms harder layers on material surfaces effortlessly. Gas nitriding has the key benefit of being independent from the sample's geometry and it does not involve special equipment. A great disadvantage entails the high temperatures necessary, around $650-1000^{\circ} \mathrm{C}$, as well as lengthy nitriding times of $1-100 \mathrm{~h}$, as reported in the literature. It is also common knowledge that gas nitriding reduces the fretting fatigue limit of aluminum alloys [101].

Plasma nitriding or ion nitriding is more preferred than gas nitriding because of advantages such as the ability to select either an $\varepsilon$ or a $\gamma$ monophase layer or even to remove the lower treatment, white layer, temperatures, and better control of thickness of the case [102]. The heat treatment makes it easier to control the dimensions and in some cases 
eliminate machining altogether [102]. Fatigue strength is notably improved by nitriding. The formation of precipitates in the diffusion layer tends to increase the hardness and create compressive residual stresses. These beneficial stresses lower the magnitude of the applied tensile stresses and hence increase the fretting fatigue life of the component.

\section{Applying Different Types of Coatings to Improve the Fretting Fatigue Life of Al 7075-T6}

5.1. PVD Coating. Puchi-Cabrera et al. [103] explored the effect of TiN coating on Al 7075-T6 substrate by magnetron sputtering PVD coating technique. The TiN-PVD coating layer contributed to considerably enhancing the fretting fatigue life of the $\mathrm{Al} 7075-\mathrm{T} 6$ substrate by $400 \%$ up to $2119 \%$ depending on the maximum alternating stress applied to the material. The improvement in fatigue life was a result mainly of the compressive residual stresses within the coating of roughly $7.08 \mathrm{GPa}$ and the excellent adhesion between the coating and the substrate. It was also reported that TiNPVD coatings maintain fine adhesion to the substrate under fretting fatigue loads [103].

Zalnezhad et al. studied the fretting fatigue life of Al7075T6 by application of TiN coating using PVD magnetron sputtering technique with the highest adhesion strength and surface hardness as well as minimum surface roughness achieved by improving the parameters of TiN coating [104]. Reportedly, fretting decreases the fatigue life for uncoated Al7075-T6 by $30 \%$ in a low cycle region and $57 \%$ in a high cycle region. The fretting fatigue lives of TiN-coated samples with high surface hardness and high adhesion increased at high cyclic fatigue by $39 \%$ and $77 \%$ and low cyclic fatigue by $61 \%$ and $16 \%$, respectively, in comparison with the uncoated samples.

From the study of Figures 16 and 17, it can be concluded that the fretting fatigue life of the TiN-coated specimens with high adhesion enhanced more than the coated specimen with higher surface hardness at low cyclic fatigue, while at high cyclic fatigue the results are reversed. This result is due to the brittleness of the TiN hard coating, where at high cyclic fatigue the cracks are propagated in the coating and then developed inside the specimen.

In another undertaking [105], ZrN-PVD coatings with $3 \mu \mathrm{m}$ thickness seemed to experience drastic decline in both the tensile and fatigue properties of an $\mathrm{Al} \mathrm{7075-T6}$ substrate. Decrease values of $28 \%$ and $43 \%$ were noted in the ultimate strength and yield strength of aluminum substrate, respectively, besides $73 \%$ to $82 \%$ reduction in fretting fatigue life. The adhesion between the coating layer and substrate appeared good under tensile loading, whereas major delamination occurred under high fatigue loads [105].

5.2. Hard Anodizing. Sarhan et al. [83] studied how the fretting fatigue life of hard-anodized aluminum alloy (AL7075T6) can be influenced by surface hardness by a series of rotary bending fatigue tests. As previously stated, pure aluminum is incapable of accepting hard anodizing. For this reason, pure

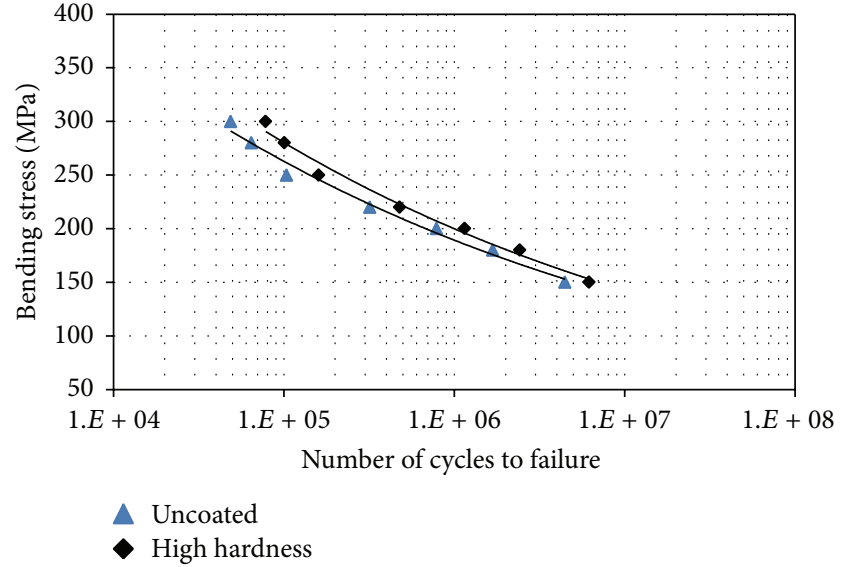

FIGURE 16: S/N curve of fretting fatigue for uncoated and TiN coated specimens with highest surface hardness [104].

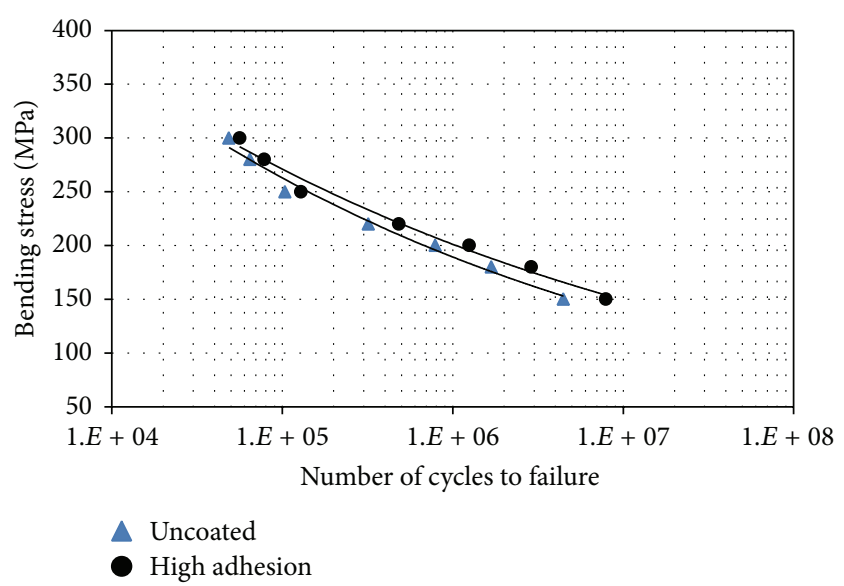

FIGURE 17: S/N curve of fretting fatigue for uncoated and TiN coated specimens with highest surface adhesion [104].

aluminum was coated on the AL7075-T6 surface. Taguchi optimization method was employed to study the influence of hard-anodized coating parameters including temperature, voltage, time, and solution concentration on surface hardness. Figures 18(a) and 18(b) demonstrate the fretting fatigue life of hard-anodized and uncoated samples with 393 and 360 HV surface hardness, respectively. Figure 18(a) indicates that at low bending stress the fretting fatigue life of hardanodized specimens with hardness of $360 \mathrm{HV}$ increased in comparison with uncoated specimens. Nonetheless, from 250 to $300 \mathrm{MPa}$, the results were reversed at high bending stress. Figure 18(b) illustrates the fretting fatigue life of uncoated and hard-anodized specimens with $393 \mathrm{HV}$ as the highest surface hardness obtained. The fretting fatigue lives of hardanodized samples increased only at low bending stresses from 150 to $200 \mathrm{MPa}$, but at a hardness of $393 \mathrm{HV}$ fretting fatigue life decreased when bending stress increased from 200 to $300 \mathrm{MPa}$. Figures 18(a) and 18(b) also indicate that the fretting fatigue lives of hard-anodized samples with surface hardness of $360 \mathrm{HV}$ increased even at $220 \mathrm{MPa}$ bending stress, while at 


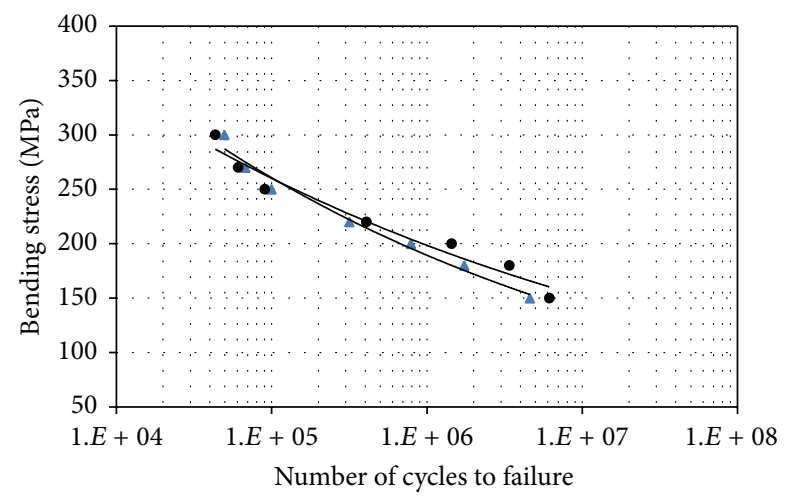

Ancoated

- Hard-anodized $360 \mathrm{HV}$

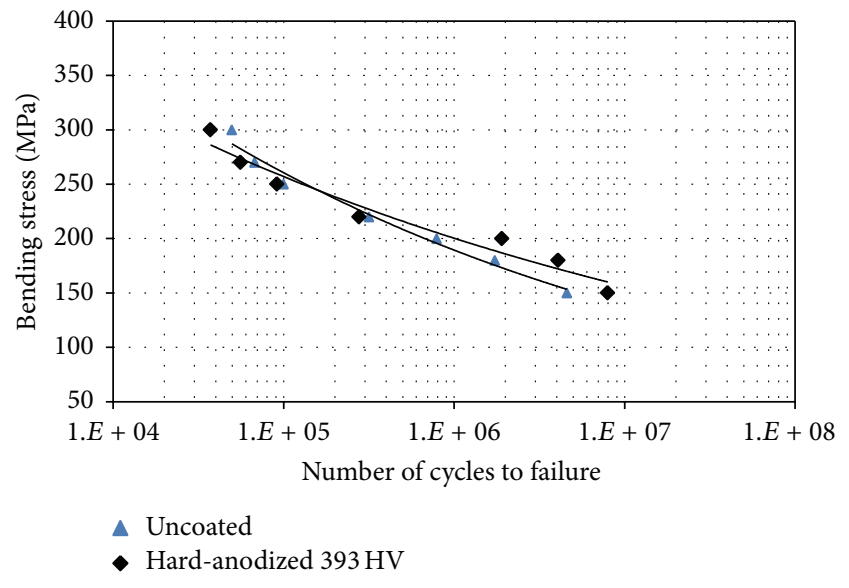

(b)

Figure 18: Comparison of $\mathrm{S} / \mathrm{N}$ curve of fretting fatigue for uncoated and hard-anodized specimen. (a) S/N curve of fretting fatigue for uncoated and hard-anodized specimens $(360 \mathrm{HV})$ and (b) S/N curve of fretting fatigue for uncoated and optimum hard-anodized parameters specimens (393 HV) [83].

this bending stress the fretting fatigue lives of hard-anodized specimen with $393 \mathrm{HV}$ hardness are decreased compared to uncoated samples. This event is due to the microcracks generation and brittleness (ceramic) of the hard-anodized specimen with higher surface hardness (higher hardness causes higher brittleness) [106-108].

It is supposed that cracks of fretting fatigue appear in regions with frictional shear stress that is locally focused on the contacting surface. Therefore, the diminishing fatigue life resulting by fretting damage is assumed to be due to shorter crack initiation life owing to concentration of local stress caused by fretting, along with accelerated propagation of initial cracks by fretting [109]. One of the principle mechanisms in the acceleration of initial cracks by fretting is considered to be the wedge effect whereby wear debris moves into the small, initial fretting fatigue crack [110]. If the crack is already completely filled with wear debris, the effect tends to be reduced because the wear debris is unable to enter the crack any more [83].

Considerable improvement is achievable through a hard anodizing surface treatment layer, which has the potential to be applied to $\mathrm{Al} 7075-\mathrm{T} 6$ and has the benefit of pure aluminum as an initial layer coated by PVD magnetron sputtering. However, this improvement is conditional to stress level.

5.3. IBED Technique. The fretting resistance and mechanisms of IBED CrN films have been assessed by $\mathrm{Fu}$ et al. [111]. The results were weighed against those of $\mathrm{CrN}$ films coated onto Al 7075-T6 via PVD. The researchers claimed that the hard IBED CrN film with sufficient substrate adhesion is capable of decreasing ploughing and subsurface distortion, consequently increasing the fretting fatigue resistance considerably, especially during operation. Also, the $\mathrm{CrN}$ phase can enhance the antioxidative and anticorrosive resistance of Ti alloy substrate during long-term fretting $[79,111]$.
One of the rationales behind IBED CrN thin film coating technique for improving fretting fatigue resistance making it superior compared to CrN film by PVD is likely attributed to the generation of a comparatively dense and fine structure due to ion beam bombardment throughout the IBED process $[86,87]$. The high adhesion strength of IBED films to the substrate is another potential explanation for the higher fretting fatigue resistance $[88,90,91]$. Under high normal load and very small slip amplitude, long cracks are generated on the surface of the fretting scar on IBED CrN films, representing fretting fatigue failure [110].

5.4. Nitriding. Nitriding treatment on Al 7075-T6 alloy has been studied by Majzoobi and Jaleh [22]. They compared fretting fatigue tests (a) without any surface modification, (b) nitriding in the absence of substrate temperature control, (c) nitriding with substrate temperature control, (d) titanium coated by magnetron sputtering PVD technique, (e) titanium coated by ion coating technique, (f) nitriding followed by titanium coating using magnetron sputtering PVD technique, and (g) nitriding followed by titanium coating done by ion coating technique. The relation of fretting fatigue versus maximum stress for the untreated aluminum alloy is illustrated in Figure 19. It is obvious that the drop in fretting fatigue life develops as long as the applied stress increases. For instance, at a stress of about $150 \mathrm{MPa}$, the decrease is approximately $60 \%$.

The fatigue test result regarding the surface modified specimens, illustrated in Figure 20, reports that fretting fatigue life for intact samples with no surface modification is much higher than nitrided samples. A couple of test series were conducted on nitrided samples in their study. In the first series of the tests, the temperature was not controlled but allowed to reach about $350^{\circ} \mathrm{C}$ during nitriding. The outcome of this series is designate by HT (high temperature) in Figure 20. In the second test series, the temperature increase along surface modification was monitored by cooling the 


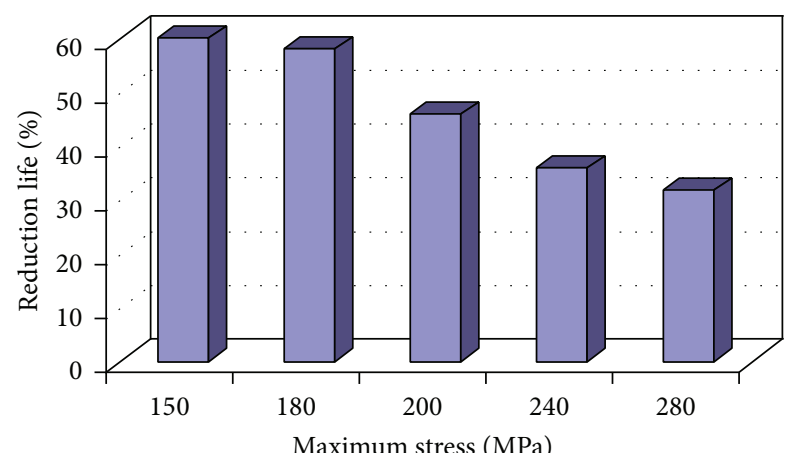

FIGURE 19: Reduction percentage of fretting fatigue life versus stress [22].

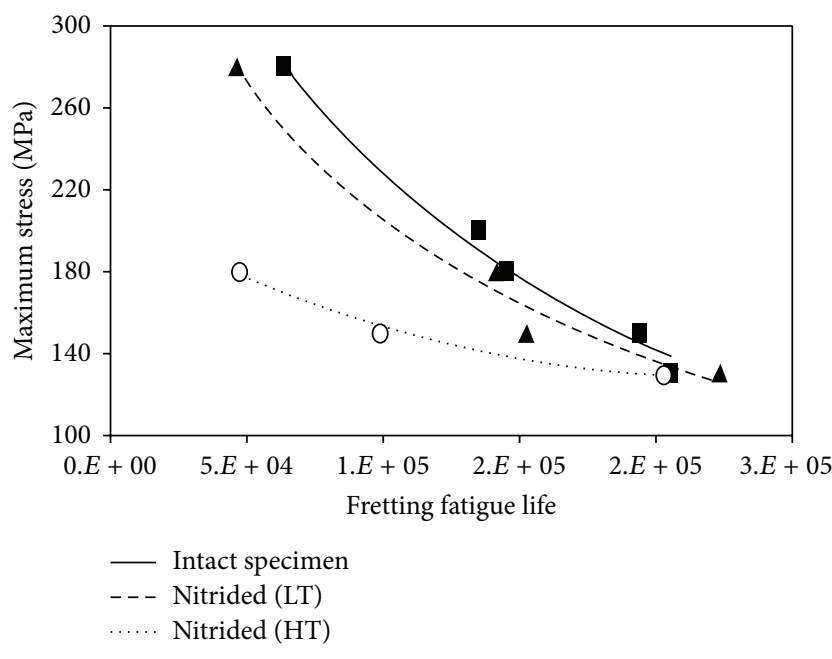

FIgURE 20: S-N curves for nitrided and normal specimens [22].

specimens. The result is indicated by LT (low temperature) as shown in Figure 20. It can be concluded that the fatigue life drastically shortened for the first series of nitrided specimens. This potentially results from the nature of the nitriding process itself, which dramatically alters the material properties, particularly its ultimate strength and yield stress. Therefore, it can be deduced that nitriding alone does not enhance the material's fretting fatigue behavior.

Majzoobi and Jaleh [22] have also studied the outcome of titanium-coated specimens and determined that none of the nitriding and titanium coating satisfactorily improved the fretting fatigue response of AL7075-T6. For this reason, further investigation was done on the influence of a duplex surface treatment technique including titanium coating plus nitriding on the Al7075-T6 fretting fatigue behavior. Two test series were assessed. The first one was conducted with the specimens initially nitrided under controlled temperature conditions followed by coating using magnetron sputtering PVD technique. The results are illustrated in Figure 21. The figure clearly demonstrates that the duplex surface treatment technique significantly enhanced the material's fretting fatigue life in testing condition. It was also observed that the influence of the duplex treatment is much better at lower

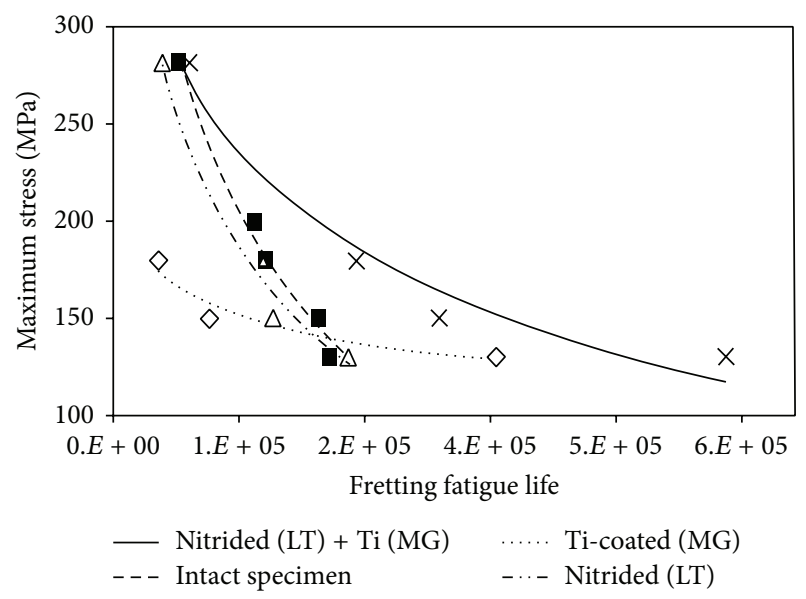

FIgURE 21: S-N curves for the duplex surface treatment, (Ni (LT) + Ti (MG)) [22].

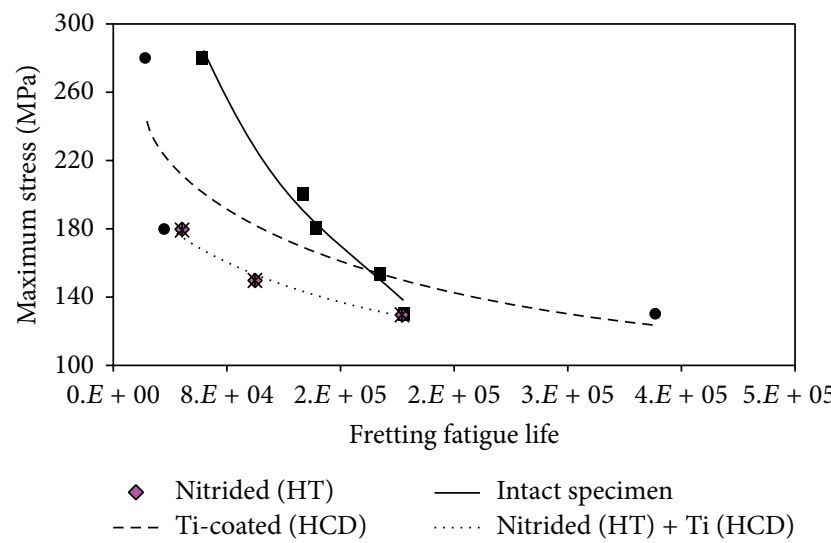

FIGURE 22: S-N curves for duplex surface treatment, $(\mathrm{Ni}(\mathrm{HT})+\mathrm{Ti}$ (HCD)) [22].

stress. As an example, the fretting fatigue life improved by nearly $100 \%$ at a stress of $130 \mathrm{MPa}$, whereas at a stress of $280 \mathrm{MPa}$ it improved only by $13 \%$.

In the second test, nitriding was followed by coating via hollow cathode deposition technique. As reported in Figure 22, a comparison of the S-N curves in the nitriding with titanium ion coating duplex treatment with the single nitriding treatment suggests that the former does not prompt any change in the performance of material with respect to resistance of fretting fatigue.

Consequently, it is asserted that the duplex surface nitriding treatment at a low temperature followed by titanium coating by PVD magnetron sputtering technique generates the optimum AL7075-T6 performance in encountering fretting fatigue damage.

\section{Discussion}

A multitude of surface modification techniques exists for decreasing fatigue damage. Significantly different mechanisms are reportedly capable of attaining this goal. At least, 
TABLE 3: Effect of surface modification techniques on fretting damage.

\begin{tabular}{|c|c|c|c|c|c|c|c|c|}
\hline $\begin{array}{l}\text { Surface } \\
\text { modification } \\
\text { method }\end{array}$ & $\begin{array}{l}\text { Decrease the } \\
\text { coefficient of } \\
\text { friction }\end{array}$ & $\begin{array}{c}\text { Introduce } \\
\text { compressive } \\
\text { stress }\end{array}$ & $\begin{array}{c}\text { Increase in } \\
\text { hardness }\end{array}$ & $\begin{array}{c}\text { Increase in } \\
\text { surface } \\
\text { roughness }\end{array}$ & $\begin{array}{c}\text { Durability or } \\
\text { adhesion }\end{array}$ & Economy & $\begin{array}{l}\text { Mitigation of } \\
\text { fretting wear }\end{array}$ & $\begin{array}{l}\text { Mitigation of } \\
\text { fretting } \\
\text { fatigue }\end{array}$ \\
\hline Nitriding & $\sqrt{ }$ & $\sqrt{ } \sqrt{ }$ & $\sqrt{ } \sqrt{ }$ & $\mathrm{D}$ & $\sqrt{ } \sqrt{ }$ & $\sqrt{ }$ & $\sqrt{ }$ & $\sqrt{ }$ \\
\hline $\begin{array}{l}\text { Electroplating } \\
\text { (Cr, Ni, etc.) }\end{array}$ & $\mathrm{D}$ & $x \times$ & $\sqrt{ }$ & $\mathrm{D}$ & $x$ & $\sqrt{ }$ & $\sqrt{ }$ & $x \times$ \\
\hline Hard anodizing & $\mathrm{D}$ & $x$ & $\sqrt{ }$ & $\mathrm{D}$ & $\sqrt{ }$ & - & $\sqrt{ }$ & $\mathrm{D}$ \\
\hline Shot peening & $x$ & $\sqrt{ }$ & $\sqrt{ }$ & $\sqrt{ } \sqrt{ }$ & - & $\sqrt{ } \sqrt{ }$ & $\sqrt{ } \sqrt{ }$ & $\sqrt{ } \sqrt{ }$ \\
\hline $\begin{array}{l}\text { Laser shock } \\
\text { peening }\end{array}$ & $\mathrm{D}$ & $\mathrm{D}$ & $\mathrm{D}$ & $\sqrt{ }$ & $x \times$ & $\sqrt{ }$ & $\mathrm{D}$ & $\sqrt{ }$ \\
\hline Deep rolling & $\sqrt{ }$ & $\sqrt{ } \sqrt{ }$ & $\sqrt{ }$ & $\mathrm{D}$ & $\sqrt{ } \sqrt{ }$ & $\sqrt{ } \sqrt{ }$ & $\sqrt{ }$ & $\sqrt{ } \sqrt{ }$ \\
\hline IBED hard film & $\sqrt{ }$ & $\sqrt{ }$ & $\sqrt{ }$ & $x \times$ & $\sqrt{ }$ & $x \times$ & $\sqrt{ } \sqrt{ }$ & $\sqrt{ } \sqrt{ }$ \\
\hline $\begin{array}{l}\text { PVD hard } \\
\text { coating }\end{array}$ & $\sqrt{ }$ & $\mathrm{D}$ & $\sqrt{ }$ & $x$ & $\mathrm{D}$ & $x$ & $\sqrt{ }$ & $\mathrm{D}$ \\
\hline
\end{tabular}

D: depending on condition; $\times$ : bad effect; $\sqrt{ }$ : good effect; $\sqrt{ } \sqrt{ }$ : very good effect, and $\times \times$ : very bad effect.

five diverse methods of increasing fretting fatigue resistance are applying compressive residual stress, reducing the friction coefficient, enhancing surface hardness, changing the surface chemistry, and increasing surface roughness. Table 3 tabulates a number of typical surface modifications applicable to Al7075-T6 alloy accompanied by their effects on fretting phenomena.

Introducing compressive residual stresses into surface layers by means of surface modification is possibly among the most substantial mechanisms of decreasing fretting damage and consequently fretting fatigue [112]. Compressive stress causes fretting fatigue crack surfaces to close up, preventing crack propagation. Not only that, but compressive stress also decreases the tensile stress of fretting, subsequently lowering the rates of wear and crack propagation [113].

Selective deposition technique and surface treatments, such as ion implantation, shot peening, nitriding, and ion beam enhanced deposition, could induce compressive residual stress. Hence, such techniques are highly recommended to obtain better fretting resistance, mainly to improve the fretting fatigue strength. It is important to be noted that some types of surface modification including laser treatments and electroplating $\mathrm{Cr}$ are not proper to be applied for fretting fatigue life improvement as tensile residual stresses are often generated $[114,115]$.

The coefficient of friction plays an important role in fretting damage since greater friction force leads to higher strain fatigue or shear stress on surfaces and at interfaces. As such, delamination cracks or intensified fatigue failure could ensue. Lower friction coefficients can enhance the fretting fatigue strength in response to the minimized alternating tensile shear stresses. Elevated alternating stresses are a cause of high local strain fatigue and rapid fatigue crack initiation. Another concern is surface hardness, whereby a dramatic increase in surface hardness is followed by high residual tensile stress and reduced toughness in the surface layer, all of which are detrimental to fretting fatigue strength.
Changing the chemistry of the surface also possibly influences fretting damage. The fundamental function of oxidation during fretting and the important influence of oxide debris are understood by many scientists. Altering the surface chemistry by nitride, oxide, or carbide layer formation may help to enhance fretting resistance by having a lubricating effect.

The surface roughness influences on fretting resistance are fairly intricate and inconsistent. Good surface finishing emphasizes fretting damage, and to minimize such damage increasing surface roughness using different treatment techniques like shot peening is sometimes helpful. In some cases, increasing surface roughness may be the cause of a rising friction coefficient, which is not proper for fretting fatigue resistance. A rough surface has the potential to elevate stress, something very dangerous, especially under fatigue conditions [116-124].

Considering surface treatment means of mitigating fretting damage, specifically for Al 7075-T6, seven techniques have been drawn and discussed in this study. These particular methods are in great demand due to the positive effect on the fretting fatigue life of this aluminum alloy [125-129].

Deep rolling is absolutely successful in increasing fretting fatigue life at high cyclic load. The rolling force affects fatigue life in elevated rolling forces to enhance fatigue life by more than two times. It is thus concluded that by increasing rolling force an improvement in fatigue life is achievable. Deep rolling is also known to maintain low surface roughness. Compared to other techniques, deep rolling creates deeper compressive residual stress layers. Nevertheless, rolling force has the drawback of necessitating optimization and control.

Shot peening also follows the deep rolling's theory. They both produce a compressive residual stress layer. The distribution and depth of residual stress are affected by a variety of parameters like shot material and diameter, duration, target material, intensity of exposure, and shot velocity.

At low cycle fatigue (LCF) tests, SP enhances the material's fretting fatigue behavior much better than DR. 
SP increased fretting fatigue life by $300 \%$ for the tested specimens. The effect of DR on fretting fatigue resistance was more pronounced in high cycle fatigue, with a recorded improvement of about $700 \%$ at higher rolling forces.

A study of reshot peening techniques shows that the fretting fatigue lives of Al7075-T6 alloy are enhanced significantly. The fretting fatigue life of Al7075-T6 improved by $600 \%$ after 5 reshot peenings. It indicates that reshot peening has superior effect than simple shot peening.

Like shot peening and deep rolling, the mitigation of fretting fatigue life of specimens by using laser shock peening depends on the compressive residual stress layer. The deeper layer penetration can be achieved by LSP compared to SP. After laser shot peening treatment, significant improvement in fretting fatigue resistance can be obtained compared to other similar techniques.

Among the heat treatment methods meant to enhance the fretting fatigue of $\mathrm{Al}$ alloy 7075-T6, nitriding has always been an excellent option. In some cases, however, the results show that the fretting fatigue life of specimens with no surface modification is much higher than nitrided specimens.

PVD metal coatings including silver and gold were traditionally used to avoid fretting failure. The augmented fatigue life with PVD comes as a result of mainly compressive residual stresses during coating, in some cases at magnitudes of 7.08 GPa, and the excellent adhesion of coating to substrate.

In surface treatments by hard thin coating techniques, it is useful to be noted that fretting has a deleterious effect on the fatigue life of AL7075-T6 in uncoated and coated conditions at any bending stress [130].

Consequently, fretting can reduce the fatigue life of uncoated Al7075-T6 by about 30\% in low cycle regions and by $57 \%$ in high cycle regions. Magnetron sputtering PVD coating in combination with hard anodizing substantially enhanced the fretting fatigue of AL7075-T6. As opposed to uncoated samples, a $119.55 \%$ enhancement in surface hardness of hard-anodized Al7075-T6 with a hardness of $393 \mathrm{HV}$ was gained. At low bending stress, the fretting fatigue life of Al7075-T6 alloy is improved by the hard-anodized coating with hardness of $360 \mathrm{HV}$ [131-134].

IBED technique demonstrates better film properties than similar films produced by PVD.

The superior ability of nitriding to enhance fretting fatigue is more evident when this technique is paired with magnetron sputtering PVD. Different studies have reported that none of nitriding and titanium coating could suitably enhance the fretting fatigue life of Al7075-T6. Hence, investigations showed the dramatic development in the fretting fatigue behavior of Al-7075-T6 when subjected to duplex surface treatment including nitriding followed by titanium coating. The duplex treatment is much more effective at lower stress. At a stress of $130 \mathrm{MPa}$, the fretting fatigue life improved by $100 \%$ but only by $13 \%$ at $280 \mathrm{MPa}$.

Accordingly, it is recognized that duplex surface treatment entailing nitriding at low temperature followed by titanium coating using magnetron-sputtering PVD technique results in the greatest Al7075-T6 performance against fretting fatigue damage.

\section{Summary}

The effects of various methods including deep rolling, shot peening, laser shock peening, thin film hard coating using physical vapor deposition (PVD), hard anodizing, ion-beamenhanced deposition (IBED), and nitriding to diminish the effect of fretting on the fatigue life of Al7075-T6 alloy are studied in detail. The following conclusions are derived.

(a) The deep rolling technique effectively improves the fretting fatigue behavior at high pressure. Increasing the rolling force increases fretting fatigue accordingly. DR maintains low surface roughness and great depth of compressive residual stress. The effect of DR on fretting fatigue resistance is deeper with high cycle fatigue, with up to $700 \%$ recorded. For low cycle fatigue (less than $10^{5}$ cycles), SP improves fretting fatigue more effectively than DR, by $300 \%$. Reshot peening technique seems to be much better than simple shot peening. After 5 reshot peenings, the fretting fatigue life of Al7075-T6 is improved by $600 \%$.

(b) The fretting fatigue life for nitrided specimens with no surface modification is significantly lower than the intact samples. However, the duplex surface treatment comprising nitriding at a low temperature plus titanium coating using magnetron sputtering technique improved the fretting fatigue of $\mathrm{Al} 7075-\mathrm{T} 6$ up to $100 \%$ at low stress. This technique could not sustain the same outcome at high stresses such as $280 \mathrm{MPa}$ where fretting fatigue rose by merely $13 \%$.

(c) Thin film hard coating is found to be a good choice for enhancing the fretting fatigue life of Al7075-T6. Fretting decreased the fatigue life of uncoated Al7075T6 by $57 \%$ in high cycle regions and $30 \%$ in low cycle regions. The fretting fatigue lives of TiN-coated specimens are improved at high cyclic fatigue by $39 \%$ and $77 \%$ and at low cyclic fatigue by $61 \%$ and $16 \%$, respectively, compared to the uncoated specimens.

(d) IBED technique demonstrates superior film properties to similar films prepared by PVD technique. Titanium coating via IBED reportedly increased the fatigue life of $\mathrm{Al}$ alloy $7075-\mathrm{T} 6$ by $100 \%$ at low working stresses.

\section{Conflict of Interests}

There are no competing or financial interests in this paper.

\section{Acknowledgments}

The authors acknowledge the financial support under the University Malaya Research Grant (Grant no. UM.TNC2/ RC/AET/GERAN (UMRG) RG133/11AET) from the University of Malaya, Malaysia. This research was partially funded by the University of Malaya under UMRG Programme Grant no. UM.TNC2/RC/AET/261/1/1/RP017-2012C. 


\section{References}

[1] R. B. Waterhouse, Fretting Corrosion, Pergamon Press, 1972.

[2] Y. Berthier, L. Vincent, and M. Godet, "Fretting fatigue and fretting wear," Tribology International, vol. 22, no. 4, pp. 235242, 1989.

[3] Y. Berthier, C. Colombie, L. Vicent, and M. Godet, "Fretting wear mechanisms and their effects on fretting fatigue," Journal of Tribology, vol. 110, no. 3, pp. 517-524, 1988.

[4] P. Forsyth, "Occurrence of fretting fatigue failures in practice," in Fretting Fatigue, pp. 99-125, 1981.

[5] D. A. Hills, "Mechanics of fretting fatigue," Wear, vol. 175, no. 1-2, pp. 107-113, 1994.

[6] R. B. Waterhouse, Fretting Fatigue, IDEAS International, 1981.

[7] R. B. Waterhouse and T. Lindley, "Fretting fatigue," in Proceedings of the International Symposium on Fretting Fatigue, Mechanical Engineering Publications, University of Sheffield, 1994.

[8] D. Taylor and R. Waterhouse, "Wear, fretting and fretting fatigue," in Metal Behavior and Surface Engineering, pp. 13-35, 1989.

[9] T. Juuma, “Torsional fretting fatigue strength of a shrink-fitted shaft with a grooved hub," Tribology International, vol. 33, no. 8, pp. 537-543, 2000.

[10] J. Sato, "Recent trend in studies of fretting wear," Journal of Japan Society of Lubrication Engineers, vol. 30, no. 12, pp. 853-858, 1985.

[11] G. H. Majzoobi, J. Nemati, A. J. Novin Rooz, and G. H. Farrahi, "Modification of fretting fatigue behavior of AL7075-T6 alloy by the application of titanium coating using IBED technique and shot peening," Tribology International, vol. 42, no. 1, pp. 121-129, 2009.

[12] J. Sato, M. Shima, T. Sugawara, and A. Tahara, "Effect of lubricants on fretting wear of steel," Wear, vol. 125, no. 1-2, pp. 83-95, 1988.

[13] S. C. Gordelier and T. C. Chivers, "A literature review of palliatives for fretting fatigue," Wear, vol. 56, no. 1, pp. 177-190, 1979.

[14] Y. Qiu and B. J. Roylance, "The effect of lubricant additives on fretting wear," Lubrication Engineering, vol. 48, no. 10, pp. 801808, 1992.

[15] R. Waterhouse, "The effect of surface treatment on the fatigue and fretting-fatigue of metallic materials," in Metal Treatments against Wear, Corrosion, Fretting and Fatigue, pp. 31-40, Pergamon Press, 1988.

[16] L. Xue, A. Koul, M. Bibby, W. Wallace, and M. Islam, "A survey of surface treatments to improve the fretting fatigue resistance of Ti-6Al-4V,' International Journal of Fatigue, vol. 18, pp. 510$510,1996$.

[17] S. J. Harris, M. P. Overs, and A. J. Gould, "The use of coatings to control fretting wear at ambient and elevated temperatures," Wear, vol. 106, no. 1-3, pp. 35-52, 1985.

[18] R. C. Bill, "Fretting of AISI 9310 steel and selected frettingresistant surface treatments," ASLE Transactions, vol. 21, no. 3, pp. 236-242, 1978.

[19] Y. Fu, J. Wei, and A. W. Batchelor, "Some considerations on the mitigation of fretting damage by the application of surfacemodification technologies," Journal of Materials Processing Technology, vol. 99, no. 1, pp. 231-245, 2000.

[20] Y. Fu, N. L. Loh, A. W. Batchelor, D. Liu, J. He, and K. Xu, "Improvement in fretting wear and fatigue resistance of Ti-6Al$4 \mathrm{~V}$ by application of several surface treatments and coatings,"
Surface and Coatings Technology, vol. 106, no. 2-3, pp. 193-197, 1998.

[21] L. Xue, M. Islam, A. K. Koul, M. Bibby, and W. Wallace, "Laser gas nitriding of Ti-6Al-4V. Part 1: optimization of the process," Advanced Performance Materials, vol. 4, no. 1, pp. 25-47, 1997.

[22] G. H. Majzoobi and M. Jaleh, "Duplex surface treatments on AL7075-T6 alloy against fretting fatigue behavior by application of titanium coating plus nitriding," Materials Science and Engineering A, vol. 452-453, pp. 673-681, 2007.

[23] D. Nowell and D. A. Hills, "Mechanics of fretting fatigue tests," International Journal of Mechanical Sciences, vol. 29, no. 5, pp. 355-365, 1987.

[24] I. Nikitin and I. Altenberger, "Comparison of the fatigue behavior and residual stress stability of laser-shock peened and deep rolled austenitic stainless steel AISI 304 in the temperature range $25-600^{\circ} \mathrm{C}$," Materials Science and Engineering A, vol. 465, no. 1-2, pp. 176-182, 2007.

[25] R. K. Nalla, I. Altenberger, U. Noster, G. Y. Liu, B. Scholtes, and R. O. Ritchie, "On the influence of mechanical surface treatments-deep rolling and laser shock peening-on the fatigue behavior of Ti-6Al-4V at ambient and elevated temperatures," Materials Science and Engineering A, vol. 355, no. 1-2, pp. 216230, 2003.

[26] T. C. Lindley, "Fretting fatigue in engineering alloys," International Journal of Fatigue, vol. 19, no. 1, pp. S39-S49, 1997.

[27] M. A. Matin, W. P. Vellinga, and M. G. D. Geers, “Thermomechanical fatigue damage evolution in SAC solder joints," Materials Science and Engineering A, vol. 445-446, pp. 73-85, 2007.

[28] M. Hirata, M. Maejima, K. Saruwatari, H. Shigeno, and M. Takaya, "Rotational bending fatigue of anodized coating of aluminum," Journal of the Surface Finishing Society of Japan, vol. 47, no. 4, pp. 376-377, 1996.

[29] A. M. Cree, G. W. Weidmann, and R. Hermann, "Film-assisted fatigue crack propagation in anodized aluminium alloys," Journal of Materials Science Letters, vol. 14, no. 21, pp. 1505-1507, 1995.

[30] P. Reybet Degat, Z. R. Zhou, and L. Vincent, "Fretting cracking behaviour on pre-stressed aluminium alloy specimens," Tribology International, vol. 30, no. 3, pp. 215-223, 1997.

[31] I. R. McColl, S. J. Harris, Q. Hu, G. J. Spurr, and P. A. Wood, "Influence of surface and heat treatment on the fretting wear of an aluminium alloy reinforced with SiC particles," Wear, vol. 203-204, pp. 507-515, 1997.

[32] R. L. Barrie, T. P. Gabb, J. Telesman et al., "Effectiveness of shot peening in suppressing fatigue cracking at non-metallic inclusions in Udimet ${ }^{\circledR}$ 720," Materials Science and Engineering A, vol. 474, no. 1-2, pp. 71-81, 2008.

[33] N. Godja, N. Kiss, C. Löcker et al., "Preparation and characterization of spark-anodized Al-alloys: physical, chemical and tribological properties," Tribology International, vol. 43, no. 7, pp. 1253-1261, 2010.

[34] R. Sadeler, S. Atasoy, A. ArIcI, and Y. Totik, "The fretting fatigue of commercial hard anodized aluminum alloy," Journal of Materials Engineering and Performance, vol. 18, no. 9, pp. 1280-1284, 2009.

[35] R. H. Oskouei and R. N. Ibrahim, "The effect of clamping compressive stresses on the fatigue life of Al 7075-T6 bolted plates at different temperatures," Materials and Design, vol. 34, pp. 90-97, 2012. 
[36] R. H. Oskouei and R. N. Ibrahim, "The effect of typical flight temperatures on the fatigue behaviour of Al 7075-T6 clamped plates," Materials Science and Engineering A, vol. 528, no. 3, pp. 1527-1533, 2011.

[37] E. Zalnezhad, A. A. D. Sarhan, and M. Hamdi, "Optimizing the PVD TiN thin film coating's parameters on aerospace AL7075T6 alloy for higher coating hardness and adhesion with better tribological properties of the coating surface," International Journal of Advanced Manufacturing Technology, vol. 64, no. 14, pp. 281-290, 2013.

[38] G. H. Majzoobi, K. Azadikhah, and J. Nemati, “The effects of deep rolling and shot peening on fretting fatigue resistance of Aluminum-7075-T6," Materials Science and Engineering A, vol. 516, no. 1-2, pp. 235-247, 2009.

[39] P. O'Hara, "Superfinishing and shot peening of surfaces to optimise roughness and stress," in Proceedings of the International Conference on Computer Methods and Experimental Measurments for Surface Treatment Effects, pp. 321-330, 1999.

[40] M. Kocan, A. Ostertag, and L. Wagner, "Shot peening and rollerburnishing to improve fatigue resistance of the $(a+\beta)$ titanium alloy Ti-6Al-4V," in Shot Peening, pp. 461-467, 2003.

[41] X. P. Jiang, C.-S. Man, M. J. Shepard, and T. Zhai, "Effects of shot-peening and re-shot-peening on four-point bend fatigue behavior of Ti-6Al-4V," Materials Science and Engineering A, vol. 468-470, pp. 137-143, 2007.

[42] R. Raghavan, R. Ayer, H. W. Jin, C. N. Marzinsky, and U. Ramamurty, "Effect of shot peening on the fatigue life of a $\mathrm{Zr}$ based bulk metallic glass," Scripta Materialia, vol. 59, no. 2, pp. 167-170, 2008.

[43] A. Ali, X. An, C. A. Rodopoulos et al., "The effect of controlled shot peening on the fatigue behaviour of 2024-T3 aluminium friction stir welds," International Journal of Fatigue, vol. 29, no. 8, pp. 1531-1545, 2007.

[44] L. Wagner and G. Lütjering, "Influence of shot peening parameters on the surface layer properties and the fatigue life of Ti6Al-4V,' in Proceedings of the Second International Conference on Shot Peening (ICSP '48), pp. 194-200, 1984.

[45] U. Martin, I. Altenberger, B. Scholtes, K. Kremmer, and H. Oettel, "Cyclic deformation and near surface microstructures of normalized shot peened steel SAE 1045," Materials Science and Engineering A, vol. 246, no. 1-2, pp. 69-80, 1998.

[46] A. Turnbull, E. R. De Los Rios, R. B. Tait, C. Laurant, and J. S. Boabaid, "Improving the fatigue crack resistance of Waspaloy by shot peening," Fatigue and Fracture of Engineering Materials and Structures, vol. 21, no. 12, pp. 1513-1524, 1998.

[47] B. P. Fairand, B. A. Wilcox, W. J. Gallagher, and D. N. Williams, "Laser shock-induced microstructural and mechanical property changes in 7075 aluminum," Journal of Applied Physics, vol. 43, no. 9, pp. 3893-3895, 1972.

[48] A. H. Clauer, B. P. Fairand, and B. A. Wilcox, "Pulsed laser induced deformation in an Fe-3 Wt Pct Si alloy," Metallurgical Transactions A, vol. 8, no. 1, pp. 119-125, 1977.

[49] A. H. Clauer, B. P. Fairand, and B. A. Wilcox, "Laser shock hardening of weld zones in aluminum alloys," Metallurgical Transactions A, vol. 8, pp. 1871-1876, 1977.

[50] B. P. Fairand and A. H. Clauer, "Laser generation of highamplitude stress waves in materials," Journal of Applied Physics, vol. 50, no. 3, pp. 1497-1502, 1979.

[51] A. Clauer, B. Fairand, and E. Metzbower, Applications of Lasers in Materials Processing, American Society for Metals, Metals Park, Ohio, USA, 1979.
[52] A. King, A. Steuwer, C. Woodward, and P. J. Withers, "Effects of fatigue and fretting on residual stresses introduced by laser shock peening," Materials Science and Engineering A, vol. 435436, pp. 12-18, 2006.

[53] P. Forget, J. L. Strude, M. Jeandin, J. Lu, and L. Castex, "Laser shock surface treatment of Ni-based superalloys," Materials and Manufacturing Processes, vol. 5, no. 4, pp. 501-528, 1990.

[54] P. Peyre and R. Fabbro, "Laser shock processing: a review of the physics and applications," Optical and Quantum Electronics, vol. 27, no. 12, pp. 1213-1229, 1995.

[55] J. P. Chu, J. M. Rigsbee, G. Banas, F. V. Lawrence, and H. E. Elsayed-Ali, "Effects of laser-shock processing on the microstructure and surface mechanical properties of Hadfield manganese steel," Metallurgical and Materials Transactions A: Physical Metallurgy and Materials Science, vol. 26, no. 6, pp. 1507-1517, 1995.

[56] P. Peyre, R. Fabbro, P. Merrien, and H. P. Lieurade, "Laser shock processing of aluminium alloys. Application to high cycle fatigue behaviour," Materials Science and Engineering A, vol. 210, no. 1-2, pp. 102-113, 1996.

[57] C. B. Dane, L. A. Hackel, J. Daly, and J. Harrison, "Shot peening with lasers," Advanced Materials and Processes, vol. 153, no. 5, pp. 37-38, 1998.

[58] P. Peyre, X. Scherpereel, L. Berthe et al., "Surface modifications induced in $316 \mathrm{~L}$ steel by laser peening and shot-peening. Influence on pitting corrosion resistance," Materials Science and Engineering A, vol. 280, no. 2, pp. 294-302, 2000.

[59] J. P. Chu, J. M. Rigsbee, G. Banaś, and H. E. Elsayed-Ali, "Laser-shock processing effects on surface microstructure and mechanical properties of low carbon steel," Materials Science and Engineering A, vol. 260, no. 1-2, pp. 260-268, 1999.

[60] G. H. Majzoobi and A. R. Ahmadkhani, "The effects of multiple re-shot peening on fretting fatigue behavior of Al7075-T6," Surface and Coatings Technology, vol. 205, no. 1, pp. 102-109, 2010.

[61] A. H. Clauer, "Laser shock peening for fatigue resistance," in Surface Performance of Titanium, J. K. Gregory, H. J. Rack, and D. Eylon, Eds., pp. 217-230, TMS, Warrendale, Pa, USA, 1996.

[62] A. H. Clauer, J. H. Holbrook, and B. P. Fairand, "Effects of laser induced shock waves on metals," in Shock Waves and HighStrain-Rate Phenomena in Metals, pp. 675-702, Springer, 1981.

[63] S. F. Design and E. Committee, SAE Manual on Shot Peening (SAE HS-84), Society of Automotive Engineers, 1991.

[64] M. Kobayashi, T. Matsui, and Y. Murakami, "Mechanism of creation of compressive residual stress by shot peening," International Journal of Fatigue, vol. 20, no. 5, pp. 351-357, 1998.

[65] G. Hammersley, L. A. Hackel, and F. Harris, "Surface prestressing to improve fatigue strength of components by laser shot peening," Optics and Lasers in Engineering, vol. 34, no. 4-6, pp. 327-337, 2000.

[66] P. S. Prevéy, M. J. Shepard, and P. R. Smith, "The effect of Low Plasticity Burnishing (LPB) on the HCF performance and FOD resistance of Ti-6AI-4V," DTIC Document, 2001.

[67] W. Z. Zhuang and G. R. Halford, "Investigation of residual stress relaxation under cyclic load," International Journal of Fatigue, vol. 23, no. 1, pp. S31-S37, 2001.

[68] S. G. Harris, E. D. Doyle, A. C. Vlasveld, J. Audy, J. M. Long, and D. Quick, "Influence of chromium content on the dry machining performance of cathodic arc evaporated TiAlN coatings," Wear, vol. 254, no. 1-2, pp. 185-194, 2003. 
[69] C.-H. Hsu and Y.-D. Chen, "A study on the abrasive and erosive wear behavior of arc-deposited Cr-N-O coatings on tool steel," Thin Solid Films, vol. 517, no. 5, pp. 1655-1661, 2009.

[70] O. Jin, S. Mall, J. H. Sanders, and S. K. Sharma, "Durability of $\mathrm{Cu}-\mathrm{Al}$ coating on Ti-6Al-4V substrate under fretting fatigue," Surface and Coatings Technology, vol. 201, no. 3-4, pp. 1704-1710, 2006.

[71] K. Schouterden, B. Blanpain, J. P. Celis, and O. Vingsbo, "Fretting of titanium nitride and diamond-like carbon coatings at high frequencies and low amplitude," Wear, vol. 181-183, no. 1, pp. 86-93, 1995.

[72] T. Liskiewicz, S. Fouvry, and B. Wendler, "Impact of variable loading conditions on fretting wear," Surface and Coatings Technology, vol. 163-164, pp. 465-471, 2003.

[73] N. Ohmae, T. Nakai, and T. Tsukizoe, "Prevention of fretting by ion plated film," Wear, vol. 30, no. 3, pp. 299-309, 1974.

[74] N. Ohmae, T. Tsukizoe, and T. Nakai, "Ion-plated thin films for anti-wear applications," Journal of Lubrication Technology, vol. 100, no. 1, pp. 129-135, 1978.

[75] B. Subramanian and M. Jayachandran, "Characterization of reactive magnetron sputtered nanocrystalline titanium nitride (TiN) thin films with brush plated Ni interlayer," Journal of Applied Electrochemistry, vol. 37, no. 9, pp. 1069-1075, 2007.

[76] J. H. Hsieh, C. Liang, C. H. Yu, and W. Wu, "Deposition and characterization of TiAlN and multi-layered TiN/TiAlN coatings using unbalanced magnetron sputtering," Surface and Coatings Technology, vol. 108-109, pp. 132-137, 1998.

[77] J.-H. Huang, K.-W. Lau, and G.-P. Yu, "Effect of nitrogen flow rate on structure and properties of nanocrystalline TiN thin films produced by unbalanced magnetron sputtering," Surface and Coatings Technology, vol. 191, no. 1, pp. 17-24, 2005.

[78] C. W. Tan and J. Miao, "Optimization of sputtered $\mathrm{Cr} / \mathrm{Au}$ thin film for diaphragm-based MEMS applications," Thin Solid Films, vol. 517, no. 17, pp. 4921-4925, 2009.

[79] B. Blanpain, H. Mohrbacher, E. Liu, J. P. Celis, and J. R. Roos, "Hard coatings under vibrational contact conditions," Surface and Coatings Technology, vol. 74-75, no. 2, pp. 953-958, 1995.

[80] H. Ezuber, A. El-Houd, and F. El-Shawesh, "A study on the corrosion behavior of aluminum alloys in seawater," Materials and Design, vol. 29, no. 4, pp. 801-805, 2008.

[81] A. Camargo and H. Voorwald, "Influence of anodization on the fatigue strength of 7050-T7451 aluminium alloy," Fatigue and Fracture of Engineering Materials and Structures, vol. 30, no. 11, pp. 993-1007, 2007.

[82] B. Rajasekaran, S. Ganesh Sundara Raman, L. Rama Krishna, S. V. Joshi, and G. Sundararajan, "Influence of microarc oxidation and hard anodizing on plain fatigue and fretting fatigue behaviour of Al-Mg-Si alloy," Surface and Coatings Technology, vol. 202, no. 8, pp. 1462-1469, 2008.

[83] A. A. D. Sarhan, E. Zalnezhad, and M. Hamdi, "The influence of higher surface hardness on fretting fatigue life of hard anodized aerospace AL7075-T6 alloy," Materials Science and Engineering A, 2012.

[84] J. A. Ghani, I. A. Choudhury, and H. H. Hassan, "Application of Taguchi method in the optimization of end milling parameters," Journal of Materials Processing Technology, vol. 145, no. 1, pp. 8492, 2004.

[85] M. Farooq and Z. H. Lee, "Computations of the optical properties of metal/insulator-composites for solar selective absorbers," Renewable Energy, vol. 28, no. 9, pp. 1421-1431, 2003.
[86] F. A. Smidt, "Use of ion beam assisted deposition to modify the microstructure and properties of thin films," International Materials Reviews, vol. 35, no. 2, pp. 61-128, 1990.

[87] J. K. Hirvonen, "Ion beam assisted thin film deposition," Materials Science Reports, vol. 6, no. 6, pp. 215-274, 1991.

[88] H. Fladry, N. Tegen, and G. K. Wolf, "Ion beam induced adhesion improvement of metal layers-a comparative study on composite layers," Nuclear Instruments and Methods in Physics Research Section B: Beam Interactions with Materials and Atoms, vol. 91, no. 1-4, pp. 575-579, 1994.

[89] G. K. Hubler, "Fundamentals of ion-beam-assisted deposition: technique and film properties," Materials Science and Engineering A, vol. 115, pp. 181-192, 1989.

[90] X.-M. He, W.-Z. Li, and H.-D. Li, "Ion beam assisted deposition of diamond-like carbon onto steel materials: preparation and advantages," Surface and Coatings Technology, vol. 84, no. 1-3, pp. 414-419, 1996.

[91] K.-H. Bäther, U. Herrmann, and A. Schröer, "Ion-beam-assisted deposition of magnetron-sputtered metal nitrides," Surface and Coatings Technology, vol. 74-75, no. 2, pp. 793-801, 1995.

[92] M. Zaytouni, J. P. Riviere, M. F. Denanot, and J. Allain, "Structural characterization of SiC films prepared by dynamic ion mixing," Thin Solid Films, vol. 287, no. 1-2, pp. 1-7, 1996.

[93] G. K. Hubler and J. A. Sprague, "Energetic particles in PVD technology: particle-surface interaction processes and energyparticle relationships in thin film deposition," Surface and Coatings Technology, vol. 81, no. 1, pp. 29-35, 1996.

[94] T. Bell, J. Lanagan, P. H. Morton, H. W. Bergmann, and A. M. Staines, "Surface engineering of titanium with nitrogen," Surface Engineering, vol. 2, no. 2, pp. 133-143, 1986.

[95] B. S. Yilbaş, A. Z. Sahin, A. Z. Al-Garni et al., "Plasma nitriding of Ti-6Al-4V alloy to improve some tribological properties," Surface and Coatings Technology, vol. 80, no. 3, pp. 287-292, 1996.

[96] S. Goudarzi, K. Khojier, H. Savaloni, and E. Zalnezhad, "On the dependence of mechanical and tribological properties of sputtered chromium nitride thin films on deposition power," Advanced Materials Research, vol. 829, pp. 352-356.

[97] S. K. Wu, H. C. Lin, and C. Y. Lee, "Gas nitriding of an equiatomic TiNi shape memory alloy. II: hardness, wear and shape memory ability," Surface and Coatings Technology, vol. 113, no. 1-2, pp. 13-16, 1999.

[98] K. C. Chen and G. J. Jaung, "D.c. diode ion nitriding behavior of titanium and Ti-6Al-4V," Thin Solid Films, vol. 303, no. 1-2, pp. 226-231, 1997.

[99] T. M. Muraleedharan and E. I. Meletis, "Surface modification of pure titanium and Ti6A14V by intensified plasma ion nitriding," Thin Solid Films, vol. 221, no. 1-2, pp. 104-113, 1992.

[100] L. Xue, M. U. Islam, A. K. Koul, W. Wallace, and M. Bibby, "Laser gas nitriding of Ti-6Al-4V alloy," Materials and Manufacturing Processes, vol. 12, no. 5, pp. 799-817, 1997.

[101] A. Zhecheva, W. Sha, S. Malinov, and A. Long, "Enhancing the microstructure and properties of titanium alloys through nitriding and other surface engineering methods," Surface and Coatings Technology, vol. 200, no. 7, pp. 2192-2207, 2005.

[102] J. M. O'Brien and D. Goodman, "Plasma (ion) nitriding," in ASM Handbook, vol. 4, pp. 420-424, ASM International, 1991.

[103] E. S. Puchi-Cabrera, F. Matínez, I. Herrera, J. A. Berríos, S. Dixit, and D. Bhat, "On the fatigue behavior of an AISI 316L stainless steel coated with a PVD TiN deposit," Surface and Coatings Technology, vol. 182, no. 2-3, pp. 276-286, 2004. 
[104] E. Zalnezhad, A. A. D. Sarhan, and M. Hamdi, "Investigating the fretting fatigue life of thin film titanium nitride coated aerospace Al7075-T6 alloy," Materials Science and Engineering A, vol. 559, pp. 436-446, 2013.

[105] E. S. Puchi-Cabrera, M. H. Staia, J. Lesage et al., "Fatigue behavior of AA7075-T6 aluminum alloy coated with $\mathrm{ZrN}$ by PVD," International Journal of Fatigue, vol. 30, no. 7, pp. 12201230, 2008.

[106] P. S. Pao, S. J. Gill, C. R. Feng, and K. K. Sankaran, "Corrosionfatigue crack growth in friction stir welded Al 7050," Scripta Materialia, vol. 45, no. 5, pp. 605-612, 2001.

[107] R. G. Rateick Jr., R. J. Griffith, D. A. Hall, and K. A. Thompson, "Relationship of microstructure to fatigue strength loss in anodised aluminium-copper alloys," Materials Science and Technology, vol. 21, no. 10, pp. 1227-1235, 2005.

[108] A. Monsalve, M. Páez, M. Toledano, A. Artigas, Y. Sepúlveda, and N. Valencia, "S-N-P curves in 7075 T7351 and 2024 T3 aluminium alloys subjected to surface treatments," Fatigue and Fracture of Engineering Materials and Structures, vol. 30, no. 8, pp. 748-758, 2007.

[109] Q. Zhang and W. Wang, "Study of anodizing behavior and corrosion resistance of 7050 T7451 alloy," Materials Science and Engineering A, vol. 280, no. 1, pp. 168-172, 2000.

[110] M. L. Sharp, G. E. Nordmark, and C. C. Menzemer, Fatigue Design of Aluminium Components and Structures, McGraw-Hill, New York, NY, USA, 1996.

[111] Y. Fu, N. Lam Loh, A. W. Batchelor, X. Zhu, K. Xu, and J. He, "Preparation and fretting wear behavior of ion-beamenhanced-deposition CrN films," Materials Science and Engineering A, vol. 265, no. 1-2, pp. 224-232, 1999.

[112] R. B. Waterhouse and A. J. Trowsdale, "Residual stress and surface roughness in fretting fatigue," Journal of Physics D: Applied Physics, vol. 25, no. 1, pp. A236-A239, 1992.

[113] G. Leadbeater, B. Noble, and R. Waterhouse, "The fatigue of an aluminium alloy produced by fretting on a shot peened surface," Advances in Fracture Research, vol. 3, pp. 2125-2132, 1986.

[114] A. J. Gould, P. J. Boden, and S. J. Harris, "Phosphorus distribution in electroless nickel deposits," Surface Technology, vol. 12, no. 1, pp. 93-102, 1981.

[115] H. Gao, H. Gu, and H. Zhou, "Sliding wear and fretting fatigue resistance of amorphous Ni-P coatings," Wear, vol. 142, no. 2, pp. 291-301, 1991.

[116] U. Bryggman and S. Söderberg, "Contact conditions and surface degradation mechanisms in low amplitude fretting," Wear, vol. 125, no. 1-2, pp. 39-52, 1988.

[117] E. Zalnezhad, A. A. D. M. Sarhan, and M. Hamdi, "Prediction of TiN coating adhesion strength on aerospace AL7075-T6 alloy using fuzzy rule based system," International Journal of Precision Engineering and Manufacturing, vol. 13, no. 8, pp. 1453-1459, 2012.

[118] G. H. Majzoobi, R. Hojjati, M. Nematian, E. Zalnejad, A. R. Ahmadkhani, and E. Hanifepoor, "A new device for fretting fatigue testing," Transactions of the Indian Institute of Metals, vol. 63, no. 2-3, pp. 493-497, 2010.

[119] E. Zalnezhad, A. A. D. M. Sarhan, and M. Hamdi, "Surface hardness prediction of $\mathrm{CrN}$ thin film coating on AL7075-T6 alloy using fuzzy logic system," International Journal of Precision Engineering and Manufacturing, vol. 14, no. 3, pp. 467-473, 2013.

[120] E. Mohseni, E. Zalnezhad, and A. R. Bushroa, "Comparative investigation on the adhesion of hydroxyapatite coating on Ti-6Al-4V implant: a review paper," International Journal of Adhesion and Adhesives, vol. 48, pp. 238-257, 2014.
[121] E. Zalnezhad, A. A. D. Sarhan, and M. Hamdi, "A fuzzy logic based model to predict surface hardness of thin film TiN coating on aerospace AL7075-T6 alloy," International Journal of Advanced Manufacturing Technology, vol. 68, pp. 415-423, 2013.

[122] M. S. Farhan, E. Zalnezhad, A. R. Bushroa, and A. A. D. Sarhan, "Electrical and optical properties of indium-tin oxide (ITO) films by ion-assisted deposition (IAD) at room temperature," International Journal of Precision Engineering and Manufacturing, vol. 14, no. 8, pp. 1465-1469, 2013.

[123] S. Baradaran, W. J. Basirun, E. Zalnezhad, M. Hamdi, A. A. D. Sarhan, and Y. Alias, "Fabrication and deformation behaviour of multilayer $\mathrm{Al}_{2} \mathrm{O}_{3} / \mathrm{Ti} / \mathrm{TiO}_{2}$ nanotube arrays," Journal of the Mechanical Behavior of Biomedical Materials, vol. 20, pp. 272282, 2013.

[124] A. A. D. Sarhan, E. Zalnezhad, and M. Hamdi, "The influence of higher surface hardness on fretting fatigue life of hard anodized aerospace AL7075-T6 alloy," Materials Science and Engineering A, vol. 1, pp. 23-40, 2012.

[125] E. Zalnezhad, A. A. D. Sarhan, and M. Hamdi, "A fuzzy logic based model to predict surface hardness of thin film TiN coating on aerospace AL7075-T6 alloy," International Journal of Advanced Manufacturing Technology, vol. 49, pp. 256-265, 2014.

[126] E. Zalnezhad, S. Baradaran, A. R. Bushroa, and A. A. D. Sarhan, "Mechanical property enhancement of Ti- $6 \mathrm{Al}-4 \mathrm{~V}$ by multilayer thin solid film $\mathrm{Ti} / \mathrm{TiO}_{2}$ nanotubular array coating for biomedical application," Metallurgical and Materials Transactions A, vol. 45, pp. 785-797, 2014.

[127] S. Goudarzi, K. Khojier, H. Savaloni, and E. Zalnezhad, "On the dependence of mechanical and tribological properties of sputtered chromium nitride thin films on deposition power," Advanced Materials Research, vol. 829, pp. 352-356, 2014.

[128] M. S. Farhan, E. Zalnezhad, and A. R. Bushroa, "Investigation of optical and structural properties of ion-assisted deposition (IAD) $\mathrm{ZrO}_{2}$ thin films," International Journal of Precision Engineering and Manufacturing, vol. 14, pp. 1997-2002, 2013.

[129] E. Zalnezhad, A. A. D. Sarhan, and M. Hamdi, "Fretting fatigue life evaluation of multilayer Cr-CrN-coated Al7075-T6 with higher adhesion strength-fuzzy logic approach," International Journal of Advanced Manufacturing Technology, vol. 69, pp. 1153-1164, 2013.

[130] M. S. Farhan, E. Zalnezhad, and A. R. Bushroa, "Properties of $\mathrm{Ta}_{2} \mathrm{O}_{5}$ thin films prepared by ion-assisted deposition," Materials Research Bulletin, vol. 48, no. 10, pp. 4206-4209, 2013.

[131] E. Zalnezhad, A. A. D. Sarhan, and M. Hamdi, "Investigating the effects of hard anodizing parameters on surface hardness of hard anodized aerospace AL7075-T6 alloy using fuzzy logic approach for fretting fatigue application," International Journal of Advanced Manufacturing Technology, vol. 68, pp. 453-464, 2013.

[132] E. Zalnezhad, A. A. D. Sarhan, and P. Jahanshahi, "A new fretting fatigue testing machine design, utilizing rotating-bending principle approach," The International Journal of Advanced Manufacturing Technology, vol. 70, pp. 2211-2219, 2014.

[133] E. Zalnezhad, A. A. D. Sarhan, and M. Hamdi, "Adhesion strength predicting of $\mathrm{Cr} / \mathrm{CrN}$ coated Al7075 using fuzzy logic system for fretting fatigue life enhancement," in Proceedings of the World Congress on Engineering and Computer Science, vol. 1, pp. 2-8, 2013.

[134] E. Zalnezhad and A. D. Ahmed Sarhan, "Multilayer thin film CrN coating on aerospace AL7075-T6 alloy for surface integrity enhancement," The International Journal of Advanced Manufacturing Technology, vol. 72, pp. 1491-1502, 2014. 

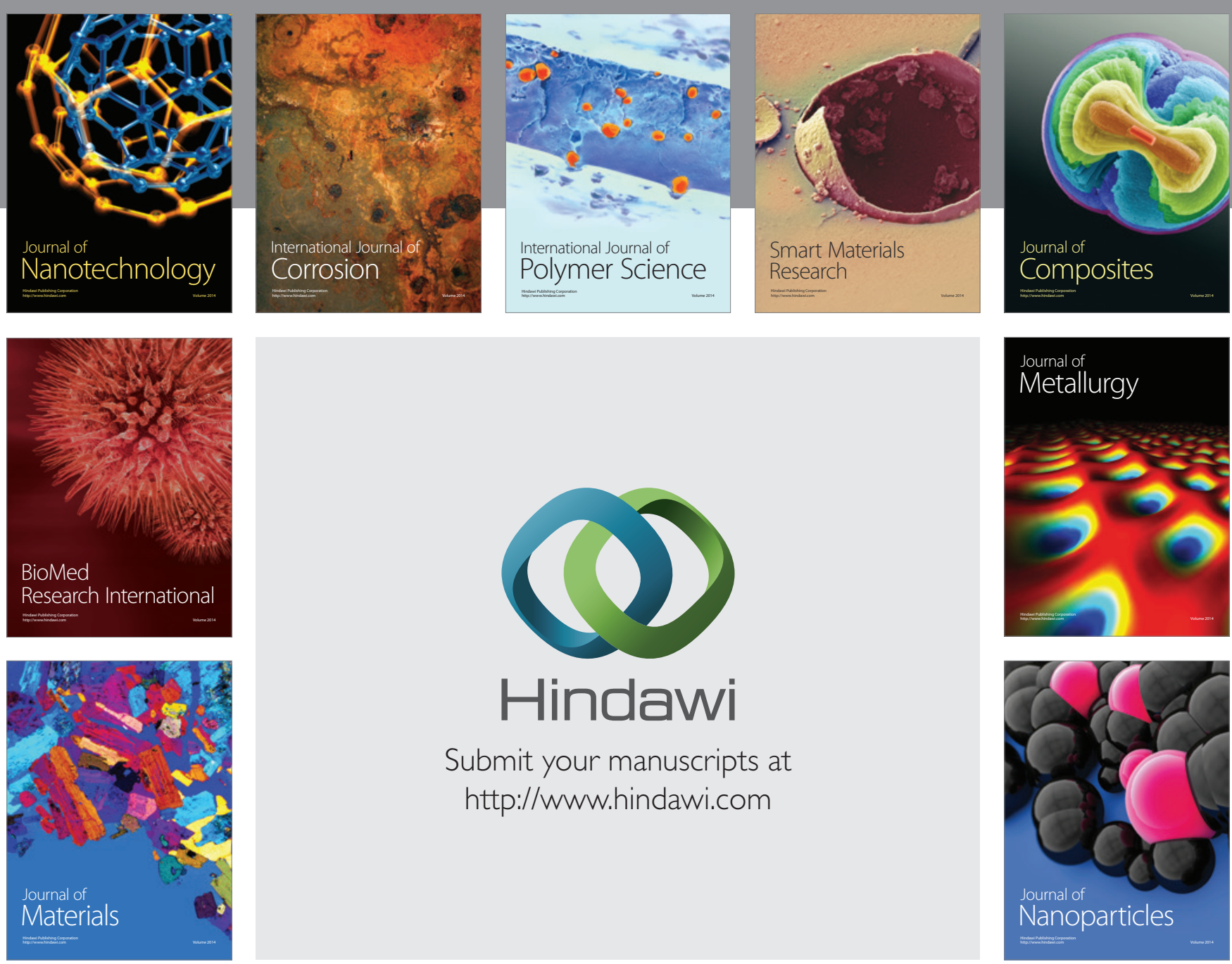

Submit your manuscripts at http://www.hindawi.com
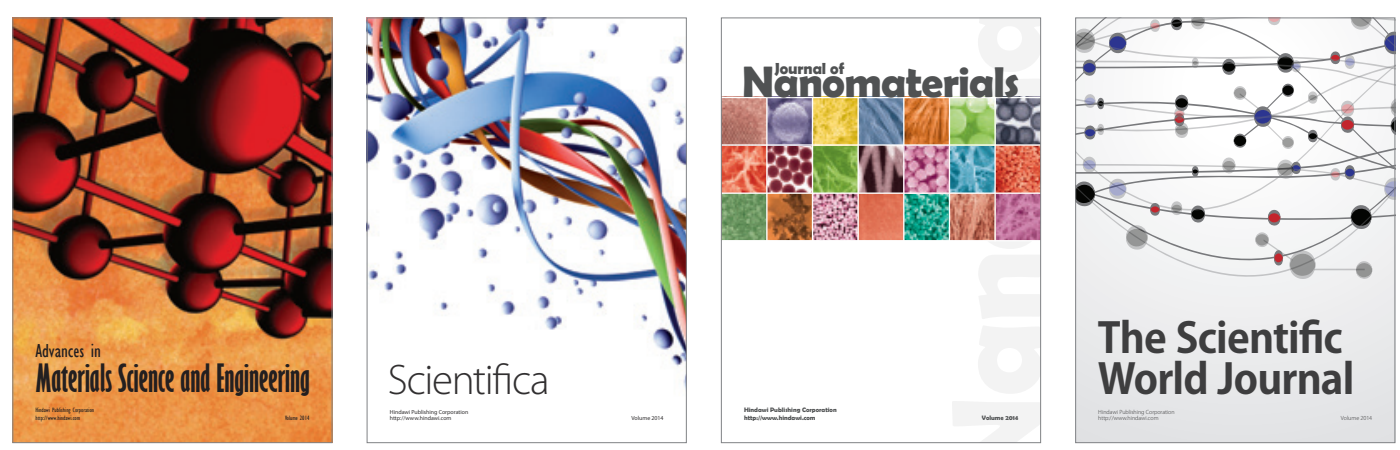

\section{The Scientific World Journal}
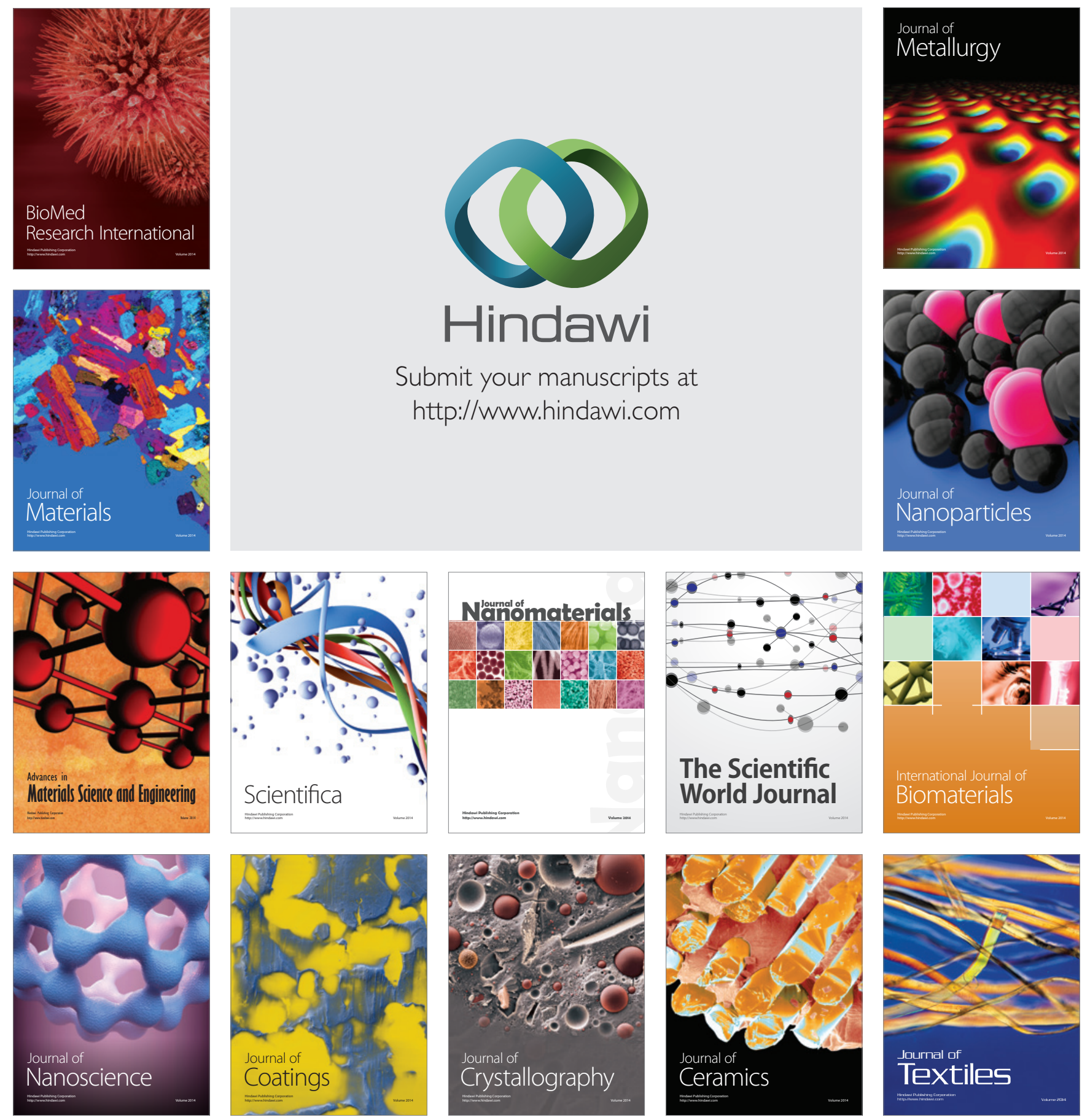